\title{
Imaging biomarkers for evaluating tumor response: RECIST and beyond
}

\author{
Ching-Chung $\mathrm{Ko}^{1,2}$, Lee-Ren Yeh ${ }^{3}$, Yu-Ting Kuo ${ }^{1,4}$ and Jeon-Hor Chen ${ }^{3,5^{*}}$ (D)
}

\begin{abstract}
Response Evaluation Criteria in Solid Tumors (RECIST) is the gold standard for assessment of treatment response in solid tumors. Morphologic change of tumor size evaluated by RECIST is often correlated with survival length and has been considered as a surrogate endpoint of therapeutic efficacy. However, the detection of morphologic change alone may not be sufficient for assessing response to new anti-cancer medication in all solid tumors. During the past fifteen years, several molecular-targeted therapies and immunotherapies have emerged in cancer treatment which work by disrupting signaling pathways and inhibited cell growth. Tumor necrosis or lack of tumor progression is associated with a good therapeutic response even in the absence of tumor shrinkage. Therefore, the use of unmodified RECIST criteria to estimate morphological changes of tumor alone may not be sufficient to estimate tumor response for these new anti-cancer drugs. Several studies have reported the low reliability of RECIST in evaluating treatment response in different tumors such as hepatocellular carcinoma, lung cancer, prostate cancer, brain glioma, bone metastasis, and lymphoma. There is an increased need for new medical imaging biomarkers, considering the changes in tumor viability, metabolic activity, and attenuation, which are related to early tumor response. Promising imaging techniques, beyond RECIST, include dynamic contrast-enhanced computed tomography $(\mathrm{CT})$ or magnetic resonance imaging (MRI), diffusion-weight imaging (DWI), magnetic resonance spectroscopy (MRS), and ${ }^{18}$ F-fluorodeoxyglucose (FDG) positron emission tomography (PET). This review outlines the current RECIST with their limitations and the new emerging concepts of imaging biomarkers in oncology.
\end{abstract}

Keywords: RECIST, Imaging biomarker, Tumor response

\section{Introduction}

Tumor response assessment is important in clinical trials and standard cancer treatments. Both tumor regression and disease progression detected by imaging biomarkers are important endpoints. Imaging biomarkers can detect the subtle changes in physiology and pathology before their clinical detection and thus act as surrogate endpoints reducing time and resources used in cancer clinical trials [1]. Besides, imaging biomarkers are also used as predictive classifiers to assist in selecting appropriate

\footnotetext{
* Correspondence: jeonhc@uci.edu

${ }^{3}$ Department of Radiology, E-DA Hospital, I-Shou University, Kaohsiung, Taiwan

${ }^{5}$ Tu \& Yuan Center for Functional Onco-Imaging, Department of Radiological Sciences, University of California, 164 Irvine Hall, Irvine, CA 92697 - 5020, USA Full list of author information is available at the end of the article
}

candidates for particular treatments [2]. Conventionally, morphologic change in tumor size is usually related to survival length and has been considered as a surrogate endpoint of therapeutic efficacy by the World Health Organization (WHO) criteria and Response Evaluation Criteria in Solid Tumors (RECIST 1.0 and 1.1 versions) (Table 1). Currently, RECIST 1.1 is the gold standard for the assessment of treatment response in solid tumors [3, 4]. Traditional chemotherapies are cytotoxic and act primarily by eliminating neoplastic cells. Therefore, a change in tumor size indicates a change in the number of neoplastic cells and has thus evolved into a radiologic biomarker of treatment response [5]. However, unlike cytotoxic drugs, molecular-targeted therapy, and immunotherapy, which have emerged in the past 15 years, can effectively interfere 
Table 1 Comparison between WHO, RECIST, and RECIST 1.1 Criteria

\begin{tabular}{|c|c|c|c|}
\hline & WHO & RECIST & RECIST 1.1 \\
\hline \multicolumn{4}{|c|}{ Lesion measurement } \\
\hline $\begin{array}{l}\text { Imaging } \\
\text { modalities }\end{array}$ & N/A & Chest X-ray, $C T$, and MRI & Chest X-ray, CT, MRI, and ${ }^{18}$ F-FDG PET \\
\hline $\begin{array}{l}\text { Limitation of } \\
\text { measurable } \\
\text { lesions }\end{array}$ & N/A & $\begin{array}{l}\cdot 10 \mathrm{~mm} \text { on spiral CT } \\
\text { - } 20 \mathrm{~mm} \text { on non-spiral CT or MRI } \\
\text { - Chest X-ray: if clearly defined } \\
\text { - Clinical: } 20 \mathrm{~mm}\end{array}$ & $\begin{array}{l}\text { - } 10 \mathrm{~mm} \text { on CT/MRI (slice thickness } \leq 5 \mathrm{~mm} \text { ), or } 2 \mathrm{x} \\
\text { slice thickness (if thickness }>5 \mathrm{~mm} \text { ) } \\
\text { - Chest X-ray: } 20 \mathrm{~mm} \\
\text { - Clinical: } 10 \mathrm{~mm} \text { (must be measurable with calipers) } \\
\text {-18 F-FDG PET: included only in the detection of new } \\
\text { lesions }\end{array}$ \\
\hline Lymph node & Unspecified & Unspecified & $\begin{array}{l}\mathrm{CT} \text { : short axis } \\
\cdot \geq 15 \mathrm{~mm} \text { is measurable, target lesion } \\
\cdot \boldsymbol{\cdot} 10-14 \mathrm{~mm} \text { is non-measurable, non-target lesion } \\
\cdot<10 \mathrm{~mm} \text { is normal }\end{array}$ \\
\hline $\begin{array}{l}\text { Method of } \\
\text { measurement }\end{array}$ & $\begin{array}{l}\text { Cross-product of the longest diameter } \\
\text { and the longest perpendicular diameter }\end{array}$ & $\begin{array}{l}\text { Longest diameter in the axial } \\
\text { plane }\end{array}$ & Longest diameter in the axial plane \\
\hline $\begin{array}{l}\text { Numbers of } \\
\text { lesions } \\
\text { measured }\end{array}$ & N/A & $\begin{array}{l}\text { up to } 10 \text { lesions ( } \leq 5 \text { in any one } \\
\text { organ) }\end{array}$ & up to 5 lesions ( $\leq 2$ in any one organ) \\
\hline \multicolumn{4}{|c|}{ Response evaluation } \\
\hline $\begin{array}{l}\text { Complete } \\
\text { Response (CR) }\end{array}$ & Disappearance of all lesions & Disappearance of all lesions & $\begin{array}{l}\text { Disappearance of all lesions and pathologic lymph } \\
\text { nodes }\end{array}$ \\
\hline $\begin{array}{l}\text { Partial Response } \\
\text { (PR) }\end{array}$ & $\geq 50 \%$ decrease in the sum of the area & $\begin{array}{l}\geq 30 \% \text { decrease in the sum of } \\
\text { the longest diameter }\end{array}$ & $\geq 30 \%$ decrease in the sum of the longest diameter \\
\hline $\begin{array}{l}\text { Stable Disease } \\
\text { (SD) }\end{array}$ & Neither PR nor PD & Neither PR nor PD & Neither PR nor PD \\
\hline $\begin{array}{l}\text { Progressive } \\
\text { Disease (PD) }\end{array}$ & $\geq 25 \%$ increase in the sum of the area & $\begin{array}{l}\geq 20 \% \text { increase in the sum of } \\
\text { longest diameters, or new } \\
\text { lesions }\end{array}$ & $\begin{array}{l}\geq 20 \% \text { increase in the sum of longest diameters } \\
\text { with an absolute increase of } \geq 5 \mathrm{~mm} \text {, or new lesions }\end{array}$ \\
\hline
\end{tabular}

CT computed tomography, MRI magnetic resonance imaging, N/A not applicable, PET positron emission tomography, RECIST Response Evaluation Criteria in Solid Tumor, WHO World Health Organization

with signaling pathways and thereby inhibit cell growth. For these new treatments, tumor necrosis or lack of tumor progression may be associated with an improvement in outcome, even in the absence of major shrinkage of tumors [6]. Thus, the assessment of morphologic changes by WHO and unmodified RECIST criteria alone may not be sufficient to estimate tumor response in patients who received new targeted therapies [6-8].

There is an increased need for reliable imaging methods associated with early tumor response considering changes in other tumor characteristics such as tumor viability, metabolic activity, and attenuation. Several studies have reported low reliability of RECIST in evaluating treatment response in different tumors, such as hepatocellular carcinoma (HCC) [9], prostate cancer [10], brain glioblastoma [11], bone metastasis [12], malignant pleural mesothelioma (MPM) [13], and disseminated or ill-defined lymphoma [14]. Therefore, various specific criteria other than RECIST for response assessment of different tumors have been proposed (Table 2) [15]. According to RECIST, the selection of targeted lesions may be different among the readers for patients with multiple lesions. Variability may include scanrescan and both intra- and inter-observer inconsistency between two repeat readings of the same scan. Tumor size changes between interval studies may arise from true tumor changes and concomitant errors in measurement.

In recent years, several advanced imaging techniques are available to quantitatively assess tumor status and predict treatment response. The new medical imaging biomarkers change radiology culture towards more quantification and standardization. Beyond RECIST, images including dynamic contrast-enhanced (DCE) computed tomography (CT) or magnetic resonance imaging (MRI), diffusion-weight MR imaging (DWI), magnetic resonance spectroscopy (MRS), ${ }^{18}$ F-fluorodeoxyglucose (FDG) positron emission tomography (PET) are emerging as promising imaging techniques in the assessment of tumor response to the new anti-cancer drugs [29]. This review evaluates the current RECIST with their limitations and the new emerging concepts of imaging biomarkers in oncology.

\section{Anatomic or morphological approaches WHO criteria}

The WHO established the first standardized approach to evaluate treatment responses of solid tumors based on 
Table 2 Summary of major tumor response assessment criteria other than RECIST

\begin{tabular}{|c|c|c|}
\hline Author / Year & Criteria & Brief description \\
\hline \multicolumn{3}{|c|}{ Hepatocellular carcinoma (HCC) } \\
\hline $\begin{array}{l}\text { Lencioni, R. et al. } \\
\text { (2010) [16] }\end{array}$ & $\begin{array}{l}\text { modified RECIST } \\
\text { (mRECIST) }\end{array}$ & $\begin{array}{l}\text { - To resolve limitations of anatomic tumor response metrics when applied RECIST } 1.1 \text { to molecular- } \\
\text { targeted therapies or locoregional therapies in HCC. } \\
\text { - Reassessment of progression that could be misinterpreted in RECIST } 1.1 \text { due to the natural progression } \\
\text { of chronic liver disease (ascites, enlargement of lymph nodes, etc.). } \\
\text { - Only well-delineated, arterially enhancing lesions can be selected as target lesions. } \\
\text { - Number of target lesions: up to } 5 \text { lesions ( } \leq 2 \text { in any one organ). } \\
\text { - Short axis of porta hepatis lymph nodes } \geq 20 \mathrm{~mm} \text { or other lymph nodes } \geq 15 \mathrm{~mm} \text { are considered as } \\
\text { malignant. }\end{array}$ \\
\hline
\end{tabular}

Brain tumor

Macdonald, D.R. et al. McDonald (1990) [17]

Wen, P.Y. et al. (2010) RANO [18]

\section{Bone metastasis}

Hamaoka, T. et al. (2004) [19]

MDA

Lymphoma

Cheson, B.D., et al. (2007) [20]

Cheson, B.D., et al. (2014) [21]

Gastrointestinal stromal tumor (GIST)

Choi, H. et al. (2007) Choi

[22]

\section{${ }^{18}$ F-FDG PET}

Young, H. et al. (1999) EORTC PET [23] response

Wahl, R.L. et al. (2009) PERCIST

[24]

Goldfarb, L. et al.

iPERCIST

(2019) [25]

Immunotherapy

Wolchok, J.D. et al. irRC (2009) [26]

Nishino, M. et al. $\quad$ irRECIST (2013) [27]

Seymour, L. et al.
- Using contrast-enhanced CT and MRI scans of the head.

- Response assessment is based on changes in tumor size (the product of the maximal cross-sectional enhancing diameters).

- Considering the use of corticosteroids and changes in the neurologic status of the patient.

- Response Assessment in Neuro-Oncology (RANO) criteria.

- An update to the McDonald Criteria which also takes into consideration of non-enhancing tumor components, and lesions on the T1/T2-weighted and fluid-attenuated inversion recovery (FLAIR) MRI sequences.

- Definition of measurability.

- Number of target lesions: up to 5 lesions.

- Pseudo-progression considered.

- MD Anderson (MDA) Bone Response Criteria.

- An approach for diagnosis and assessment of bone metastasis.

- Quantitative and qualitative assessments of the behavior of bone metastases based on $x$-ray, CT, and MRI.

- Definition of standardized response criteria for Hodgkin's and non-Hodgkin's lymphoma using ${ }^{18} \mathrm{~F}$ FDG PET, immunohistochemistry, and flow cytometry.

- Represent a set of revised recommendations regarding the use of the Cheson criteria and Deauville five-point scale, and formally incorporated ${ }^{18}$ F-FDG PET into standard staging and response evaluation for FDG-avid lymphomas.

- CT criteria for evaluation of response to imatinib therapy in gastrointestinal stromal tumor (GIST).

- Combination of tumor size and tumor attenuation on CT (a $10 \%$ decrease in tumor size or a more than $15 \%$ decrease in tumor attenuation at 2 months of treatment) were used.

- Defining progressive disease by (1) appearance of new lesions, (2) appearance or increase in size of intratumoral nodules, or (3) tumor size increase by more than $20 \%$ without post-treatment hypodense change.

- European Organization for Research and Treatment of Cancer (EORTC) PET response.

- Proposed a common method of assessing tumor ${ }^{18}$ F-FDG uptake and reporting of response data.

- PET Response Criteria in Solid Tumors (PERCIST).

- Qualitative and quantitative approaches to metabolic tumor response assessment with ${ }^{18}$ F-FDG PET.

- Immune PET Response Criteria in Solid Tumors (iPERCIST).

- Monitoring anti-programmed cell death 1 (PD-1)-based immunotherapy in non-small cell lung cancer with ${ }^{18}$ F-FDG PET.

- The immune-related Response Criteria (irRC)

- Bidimensional (the product of the maximal cross-sectional diameters).

- Selection of 5 lesions ( $\geq 5 \times 5 \mathrm{~mm}$ ) per organ (up to 10 visceral and 5 cutaneous ones).

- New lesions are incorporated into the total tumor burden, do not immediately mean progressive disease (PD).

- The immune-related Response Evaluation Criteria in Solid Tumors (irRECIST) criteria.

- Unidimensional (longest diameter).

- Maximum 5 (2 per organ) lesions ( $\geq 10 \mathrm{~mm}$ in diameter; $\geq 15 \mathrm{~mm}$ for nodal lesions).

- New lesions are incorporated in the total measured tumor burden, do not immediately mean PD.

- The immune Response Evaluation Criteria in Solid Tumors (iRECIST) criteria. 
Table 2 Summary of major tumor response assessment criteria other than RECIST (Continued)

\begin{tabular}{|c|c|c|}
\hline Author / Year & Criteria & Brief description \\
\hline (2017) [28] & & $\begin{array}{l}\text { - Unidimensional (longest diameter). } \\
\text { - Maximum } 5 \text { ( } 2 \text { per organ) lesions ( } \geq 10 \mathrm{~mm} \text { in diameter; } \geq 15 \mathrm{~mm} \text { for nodal lesions). } \\
\text { - New lesions are recorded separately, not included in the sum of lesions for target lesions identified at } \\
\text { baseline. } \\
\text { - Defining unconfirmed progressive disease (iUPD) and confirmed progressive disease (iCPD). } \\
\text { - iCPD: if additional new lesions appear or an increase in size of new lesions ( } \geq 5 \mathrm{~mm} \text { for sum of new } \\
\text { target lesion or any increase in new non-target lesion) on next cross-sectional imaging after iUPD. }\end{array}$ \\
\hline
\end{tabular}

imaging studies in 1979 [30]. However, the WHO criteria (Table 1) were no longer used after 2000, because of some problems such as the interobserver variability of the number of lesions, selection of measurable targets, minimum lesion size, the definition of progressive disease (PD), and more reliable measures on new imaging technologies had emerged [31].

\section{RECIST 1.0 and RECIST 1.1}

RECIST guidelines were published in 2000 by an association that comprised the National Cancer Institute of the United States, the European Organization for Research and Treatment in Oncology, and the National Cancer Institute of Canada [3]. The original RECIST version 1.0, provided definitions for "measurable lesion" and "non-measurable lesion" (Table 1). Measurable lesions must have the longest diameter of $\geq 10 \mathrm{~mm}$ on CT with a slice thickness of $\leq 5 \mathrm{~mm}$ or the longest diameter of $\geq 20 \mathrm{~mm}$ on chest radiography [3]. Non-measurable lesions include other lesions that do not meet the criteria as measurable lesions, such as small lesions with a longest diameter less than $10 \mathrm{~mm}$, bone metastases without a soft-tissue component, pleural tumor seeding, lymphangitic tumor spread, and peritoneal or leptomeningeal tumor diseases. After identifying measurable and non-measurable lesions, the RECIST includes the terms "target" and "non-target" lesions. Target lesions are selected based on their size (lesions with the longest diameters) and suitability/conspicuity for accurate repeated measurements. Target lesions include all measurable lesions (up to 5 per organ and 10 in total) that are recorded and measured at baseline. All other lesions were identified as non-target lesions. As several questions emerged, a revised RECIST guideline (RECIST 1.1) was developed in 2009 (Table 1) [4]. Major changes in RECI ST 1.1 include the number of target lesions, assessment of pathologic lymph nodes, redefinition of disease progression, clarification of unequivocal progression of nontarget lesions, and inclusion of ${ }^{18}$ F-FDG PET in the detection of new lesions [4]. In RECIST 1.1, the maximum number of target lesions per organ was reduced from 5 to 2 , and 10 to 5 in total. Besides, lymph nodes with a short axis $\geq 15 \mathrm{~mm}$ were considered measurable, pathological, and assessable as target lesions. Lymph nodes with a short axis $<10 \mathrm{~mm}$ were considered normal.
Lymph nodes with a short-axis between 10 and $15 \mathrm{~mm}$ were identified as non-measurable, non-target lesions. Major changes from the WHO criteria to RECIST 1.1 are summarized in Table 1.

Evaluation of overall response in RECIST 1.1 is based on tumor responses in target and nontarget lesions (Table 3). For example, if there is any new lesion, the overall response is always $\mathrm{PD}$. In the absence of a new lesion, complete response (CR) is the complete disappearance of all target and nontarget lesions. However, several studies have reported the low reliability of RECI ST 1.1 in evaluating treatment response in certain tumors. In $\mathrm{HCC}$, a viable tumor is defined as showing intratumoral arterial enhancement on dynamic CT or MRI. Therefore, measurement of tumor enhancement is used as a surrogate biomarker of a viable tumor (Fig. 1), and tumor necrosis induced by treatment is considered as a response assessment [9]. Several specific criteria other than RECIST for HCC have thus been developed. The criteria include modified RECIST [16] (Table 2), European Association for the Study of the Liver (EASL) criteria [9], and the Response Evaluation Criteria in Cancer of the Liver (RECICL) criteria [32]. The RECIST is also not effective in evaluating treatment response for prostate cancer as there is not enough objective and meaningful measurement of disease progression [10]. In neuro-oncology, RECIST has limited use as the unidimensional measurements do not accurately measure the irregular or asymmetric margins of glioblastoma; besides, it did not take the use of steroids or clinical status into account [11]. The Response Assessment in NeuroOncology (RANO) criteria (Table 4) based on McDonald criteria in 2010 contemplated on non-enhancing tumor lesion on T1/T2-weighted imaging and fluid-attenuated inversion recovery (FLAIR) MRI. For bone metastasis, RECIST is limited to measurable metastases or unequivocal progression of the unmeasurable disease. For an accurate response assessment of bone metastases requires visualizing the tumor size as well the structural and metabolic changes in the bone (Fig. 2). This was addressed by the MD Anderson (MDA) bone response criteria (supplemental file) which updated the WHO criteria by expanding radiographic assessment and incorporating both CT and MRI [12, 19]. In MPM, the measurement of the longest unidimensional diameter in 
Table 3 Assessment of Treatment Response in RECIST 1.1 Criteria

\begin{tabular}{llll}
\hline Overall Response & Target Lesions & Non-Target lesions & New lesions \\
\hline$C R$ & $C R$ & CR & No \\
$P R$ & $C R$ & Non-CR or non-PD & No \\
$P R$ & $C R$ & Not evaluated & No \\
$P R$ & $P R$ & Non-PD or not all evaluated & No \\
SD & SD & Non-PD or not all evaluated & No \\
NE & Not all evaluated & Non-PD & Yes or No \\
$P D$ & $P D$ & Any & Yes or No \\
$P D$ & Any & PD & Yes \\
$P D$ & Any & Any & \\
\hline
\end{tabular}

$C R$ complete response, $N E$ not suitable to evaluation, $P D$ progressive disease, $P R$ partial response, $S D$ stable disease

tumor mass along the curved chest wall before and after the treatment is difficult that resulted in the development of modified RECIST. The modified RECIST for MPM considers tumor thickness perpendicular to fixed structures such as the chest wall or mediastinum in two positions on the same transverse slice of CT scan, and a sum of six measured values on three different levels was used for evaluation (Fig. 3) [13]. In 1999, an international working group of clinicians, radiologists, and pathologists published Cheson criteria for response assessment and outcomes measurement in lymphoma [33]. Cheson criteria were adopted widely by clinicians and were used in the approval process for several new agents. However, the Cheson criteria were revised in 2007 because of identified limitations and the increased use of ${ }^{18}$ F-FDG PET, immunohistochemistry, and flow cytometry in lymphoma. For lymphoma, the current standard response criteria are the revised Cheson criteria [20] (Table 5) and Lugano criteria [21] (supplemental file) based on PET or bidimensional tumor measurements on CT for non-FDG avid lesions [21]. In revised Cheson criteria, target lesions are defined based on the different organs (lymph nodes, liver or spleen, other organs) by both CT and PET scans, as well as the clinical examination and bone marrow biopsy. The
Lugano classification, published in 2014, eliminated ambiguity and improved evaluations in lymphoma. It included standardized staging criteria for FDG-avid lymphomas using a five-point (Deauville) scale, defined splenomegaly as $>13 \mathrm{~cm}$ based on CT image, removed requirements for bone marrow biopsy for routine staging in Hodgkin's lymphoma and most diffuse B-cell lymphoma, and revised the definitions for PD.

In recent years, new cancer immunotherapies such as immune checkpoint inhibitors, especially for advanced nonsmall cell lung cancer (NSCLC), have drawn greater attention [34]. Due to their peculiar mechanism, immunotherapies can determine unusual response patterns on imaging that cannot be correctly evaluated with the traditional RECI ST. Several immune-related response criteria including irRC, irRECIST, and iRECIST were proposed and applied in clinical trials for immunotherapies (Table 2). One of the most common and challenging condition for the morphological evaluation of the response is the "pseudo-progression", a condition where the target lesion continues to grow at the first imaging study and then remains stable, shrinks in size, or disappears during the subsequent imaging follow-up (Fig. 4). The proposed hypotheses for these morphologic changes include (i) persistent tumor growth during the

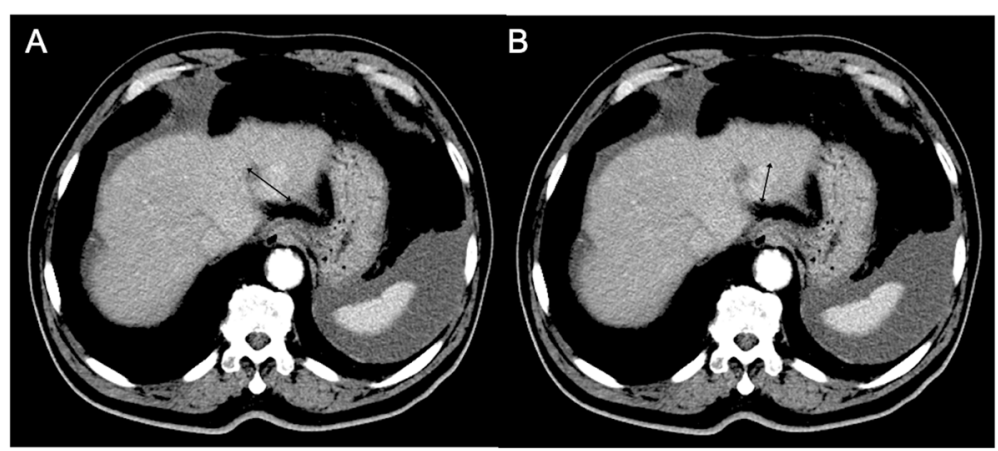

Fig. 1 Application of modified Response Evaluation Criteria in Solid Tumors (mRECIST) for hepatocellular carcinoma (HCC). A Measurement of the longest overall target tumor diameter $(41 \mathrm{~mm})$ according to conventional RECIST. B Measurement of the longest viable tumor diameter (30 mm) based on tumor enhancement area on arterial-phase CT imaging according to mRECIST for HCC 
Table 4 Response Assessment in Neuro-Oncology (RANO) Criteria

\begin{tabular}{|c|c|c|c|c|}
\hline Criterion & CR & PR & SD & PD \\
\hline T1WI with CE & None & $\geq 50 \% \downarrow$ & $<50 \% \downarrow$ but $<25 \% \uparrow$ & $\geq 25 \% \uparrow^{a}$ \\
\hline T2WI/FLAIR & Stable or $\downarrow$ & Stable or $\downarrow$ & Stable or $\downarrow$ & $\uparrow^{a}$ \\
\hline New lesion & None & None & None & Present $^{a}$ \\
\hline Corticosteroid & None & Stable or $\downarrow$ & Stable or $\downarrow$ & $N / A^{b}$ \\
\hline Clinical Status & Stable or $\uparrow$ & Stable or $\uparrow$ & Stable or $\uparrow$ & $\downarrow^{a}$ \\
\hline Response Requirement & All & All & All & Any $^{a}$ \\
\hline
\end{tabular}

$C E$ contrast enhancement, $C R$ complete response, FLAIR fluid attenuated inversion recovery, $P D$ progressive disease, $P R$ partial response, $S D$ stable disease, T1WI T1-weighted MR imaging, T2WI T2-weighted MR imaging

aprogression occurs when any this criterion is present

${ }^{\mathrm{b}} \mathrm{N} / \mathrm{A}$ not applicable

immune response mounting and/or (ii) the inflammatory process of the existing lesions and other lesions initially not visible on imaging, caused by hyper-activated T-cells [35]. Pseudo-progression has been reported for anti-programmed cell death protein-1 (anti-PD-1), anti-programmed deathligand 1 (anti-PD-L1), and anti-cytotoxic T lymphocyteassociated antigen 4 (anti-CTLA-4) agents not only in lung cancer but also other cancers, including melanoma, renal cell carcinoma, and bladder cancer [35-37].

\section{Special considerations in lung cancer}

Conventionally, lung cancer size is generally measured on lung window imaging and includes both ground-glass opacity (GGO) and solid components. The size of GGO within lung cancer generally does not vary markedly even after effective chemotherapy. Therefore, size change in the solid component of part-solid lung cancer may be a more accurate reflection of the actual tumor response to anti-cancer chemotherapy. Besides, intratumoral cavitation and necrosis caused by antiangiogenesis may also indicate tumor response (Figs. 5 and 6). Lee et al. [38] proposed a CT response criterion based on consideration of tumor components (GGO and solid part) and the presence of cavitation, necrosis, and attenuation changes for response assessment in NSCLC patients who underwent epidermal growth factor receptor (EGFR) tyrosine kinase inhibitor (TKI) thertabapy (Figs. 5 and 6).

\section{Special considerations in bone metastasis}

Bone is one of the most common metastatic sites in lung cancer, breast cancer, or prostate cancer $[39,40]$.

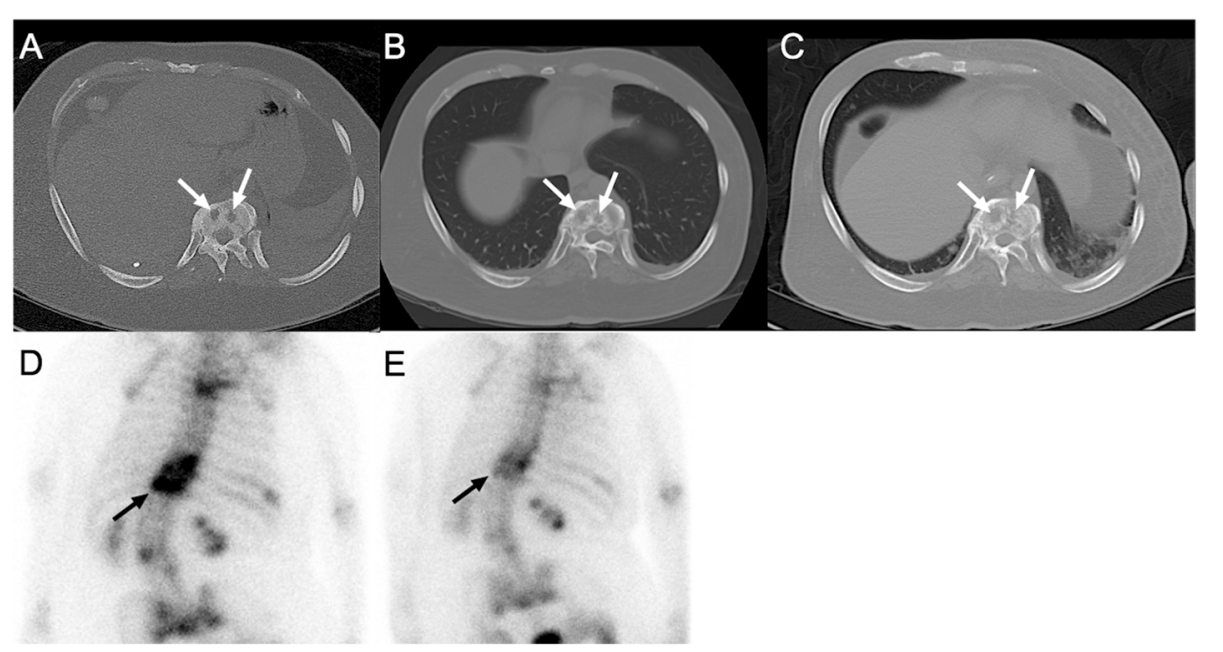

Fig. 2 Bone density changes suggest tumor response in bone metastases. A 42-year-old man was diagnosed with lung adenocarcinoma and bone metastases. A Pretreatment axial CT scan in the bone window shows two osteolytic metastases (both lesions with diameters of $10 \mathrm{~mm}$ ) (white arrows) in thoracic vertebrae. B, C The osseous lesions have not significantly changed in the sum of longest diameters according to RECI ST 1.1 but show osteosclerotic reaction (white arrows) in 6 months (B) and 10 months (C) after targeted therapy with afatinib, an epidermal growth factor receptor (EGFR) - tyrosine kinase inhibitor (TKI), representing good response. D, E Skeletal scintigraphy shows significantly decreased uptake of radiotracer after comparison between pretreatment (D) and posttreatment (E) images, which confirmed good therapeutic response 


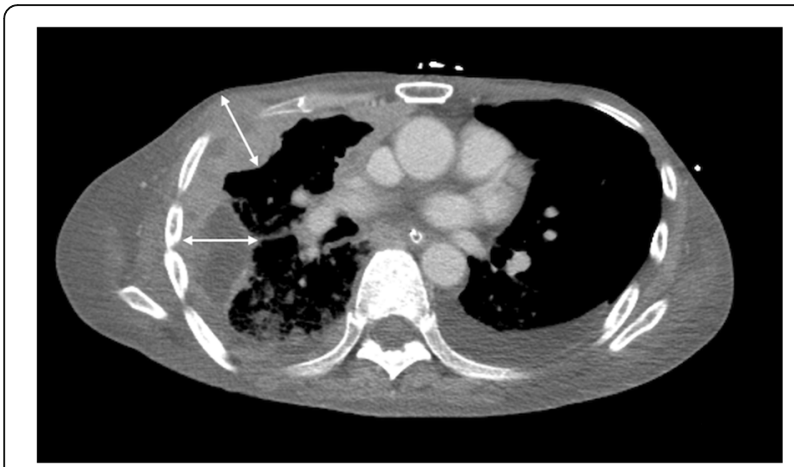

Fig. 3 Measurement of tumor thickness for tumor burden assessment in malignant pleural mesothelioma (MPM) according to modified RECIST. The tumor thickness is measured perpendicularly to the chest wall (arrows) or mediastinum, not measuring the tumor longest diameter. The sum of six measured values from two different positions on three different levels is used as modified RECI ST in MPM

Treatments for bone metastasis include chemotherapy and endocrine therapy. The treatment response is evaluated by imaging modalities such as radiography, skeletal scintigraphy, CT and MRI, and PET. Accurate response assessment of bone metastases requires evaluation of both the tumor burden and the osteolytic or osteoblastic changes in the bone lesion (Fig. 2). As the RECIST focuses predominantly on the physical measurement of solid tumors, bone metastasis is not easily measured with a ruler and is designated as unmeasurable. Patients with only bone metastases after resection of a primary tumor are not eligible for clinical trials due to no measurable disease. Therefore, the absence of measurable tumors can significantly influence treatments in these patients. The MDA criteria (supplemental file) incorporates information from $\mathrm{CT}$ imaging into that of the WHO criteria, specifically for the response assessment in bone metastases. It divides tumor response into 4 standard categories and includes quantitative and qualitative evaluation of the bone metastases. Hamaoka et al. [19] reported that the MDA criteria are superior to the WHO criteria in predicting progression-free survival in breast cancer patients with bone metastasis. In comparison to RECIST 1.1, the MDA criteria allow more metastatic bone lesions to be considered as a measurable disease by allowing physical measurement of well-defined bone lesions regardless of soft tissue extension, allowing subjective assessment of illdefined lesions, and considering healing sclerosis. Other functional imaging criteria such as Positron Emission Tomography Response Criteria in Solid Tumors (PERC IST) (Table 6) allow bone metastases to be measured by assessing tumor metabolism in the absence of anatomic change [12].

\section{Clinical limitations and challenges of morphological evaluation}

According to RECIST, the standard method to assess the response of solid tumors to chemotherapy is to decide those target lesions first and perform a uni-

Table 5 Revised Cheson Criteria for Malignant Lymphoma

\begin{tabular}{|c|c|c|c|c|}
\hline Response & Definition & Nodal masses & Spleen, Liver & Bone marrow \\
\hline$C R$ & $\begin{array}{l}\text { Disappearance of all } \\
\text { evidence of disease }\end{array}$ & $\begin{array}{l}\text { - FDG-avid or PET positive prior to ther- } \\
\text { apy; mass of any size permitted if PET } \\
\text { negative } \\
\text { - Variably FDG-avid or PET negative; re- } \\
\text { gression to normal size on CT }\end{array}$ & Not palpable, nodules disappeared & $\begin{array}{l}\text { Infiltrate cleared on repeat } \\
\text { biopsy; if indeterminate by } \\
\text { morphology, } \\
\text { immunohistochemistry should } \\
\text { be negative }\end{array}$ \\
\hline PR & $\begin{array}{l}\text { Regression of } \\
\text { measurable disease } \\
\text { and no new sites }\end{array}$ & $\begin{array}{l}\geq 50 \% \text { decrease in SPD of up to } 6 \text { largest } \\
\text { dominant masses; no increase in size of } \\
\text { other nodes; } \\
\text { - FDG-avid or PET positive prior to ther- } \\
\text { apy; one or more PET positive at previ- } \\
\text { ously involved site } \\
\text { - Variably FDG-avid or PET negative; re- } \\
\text { gression on CT }\end{array}$ & $\begin{array}{l}\geq 50 \% \text { decrease in SPD of nodules } \\
\text { (for single nodule in greatest } \\
\text { transverse diameter); no increase in } \\
\text { size of liver or spleen }\end{array}$ & $\begin{array}{l}\text { Irrelevant if positive prior to } \\
\text { therapy; cell type should be } \\
\text { specified }\end{array}$ \\
\hline $\begin{array}{l}\text { PD or } \\
\text { relapsed } \\
\text { disease }\end{array}$ & $\begin{array}{l}\text { Any new lesion or } \\
\text { increase by } \geq 50 \% \text { of } \\
\text { previously involved } \\
\text { sites from nadir }\end{array}$ & $\begin{array}{l}\text { Appearance of a new lesion(s) }>1.5 \mathrm{~cm} \text { in } \\
\text { any axis, } \geq 50 \% \text { increase in SPD of more } \\
\text { than one node, or } \geq 50 \% \text { increase in } \\
\text { longest diameter of a previously } \\
\text { identified node }>1 \mathrm{~cm} \text { in short axis; } \\
\text { lesions PET positive if FDG-avid lymph- } \\
\text { oma or PET positive before therapy }\end{array}$ & $\begin{array}{l}>50 \% \text { increase from nadir in the } \\
\text { SPD of any previous lesions }\end{array}$ & New or recurrent involvement \\
\hline SD & $\begin{array}{l}\text { Not meet above } \\
\text { criteria }\end{array}$ & $\begin{array}{l}\text { - FDG-avid or PET positive prior to ther- } \\
\text { apy; PET positive at prior sites of disease } \\
\text { and no new sites on CT or PET } \\
\text { - Variably FDG-avid or PET negative; no } \\
\text { change in size of previous lesions on CT }\end{array}$ & & \\
\hline
\end{tabular}

$C R$ complete remission, FDG fluorodeoxyglucose, $P D$ progressive disease, $P E T$ positron emission tomography, $P R$ partial remission, $S D$ stable disease, $S P D$ sum of the product of the diameters 


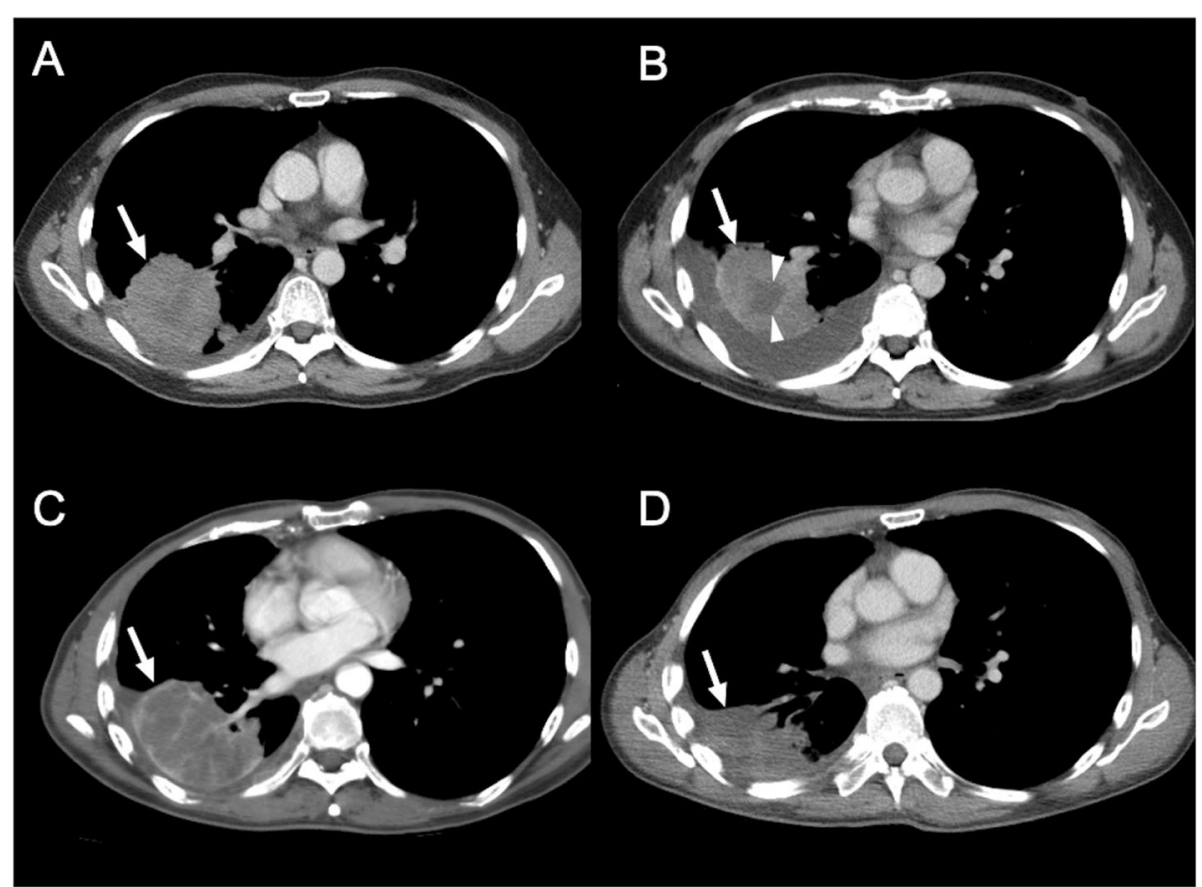

Fig. 4 Tumor necrosis indicates early good response in non-small cell lung cancer (NSCLC) receiving targeted therapy. A 53-year-old man diagnosed with NSCLC (positive EGFR exon 20 insertion mutations) and received afatinib therapy. A Pretreatment contrast-enhanced (CE) axial CT scan shows an enhancing tumor (arrow), with diameter of $64 \mathrm{~mm}$. B, C Pseudo-progression with increased tumor size (arrow) was observed in 3 months (B) $(67 \mathrm{~mm}$ in tumor diameter) and 8 months (C) $(74 \mathrm{~mm}$ in tumor diameter) after targeted therapy. Simultaneously, the progression of focal tumor necrosis (arrowheads in figure B) to diffuse tumor necrosis (C) was also observed. D Shrinkage of tumor mass (50 mm in diameter) was observed 15 months after therapy

dimensional measurement of tumor size. For patients with multiple lesions, the selection of targeted lesions in different organ may be different among the operators. Linear measurements of tumor size may have limitations related to variability in technical and imaging factors, tumor enhancement and morphology, and reader decisions [41]. These factors result in the challenge for the comparison of tumor size change over time. Tumor size changes between interval studies, including true tumor changes and concomitant variations or errors in measurement. Variability can be caused by scan-rescan variability and both intra- and inter-observer variability between two repeat readings of the same scan. Oxnard et al. [42] reported that changes of tumor size less than $10 \%$ can be a result of the inherent variability in patients with advanced NSCLC. This variability was the greatest in the measurement of small tumors and the significant importance for the accurate determination of disease progression.

The measurement of the entire tumor volume overcomes some of the limitations, as to improve the ability to reliably detect small changes in measurements, and to increase statistical power per subject in trials [43]. Neither the RECIST nor the WHO criteria include volume measurement because of limitations in past diagnostic imaging techniques and the available measurement methods. But with the advent of thin-section CT and commercially available tumor segmentation software, it is now possible to obtain image data sets with spatial resolutions adequate to measure tumor volumes [44]. Zhao et al. [45] suggested that measuring volumetric changes in tumor dimension may hold the potential to be an earlier biomarker of tumor regression or progression. The changes in tumor volume may be assessed as early as 3 weeks after the initiation of gefitinib (Iressa) treatment, whereas a lower magnitude of changes in unidimensional and bidimensional measurements was seen during the same period [45].

\section{Functional, metabolic, and other non-morphological approaches}

Functional and metabolic imaging techniques can integrate pathological, physiological, and morphological changes, and serve as potential early predictors for therapeutic response $[24,46]$. The microscopic changes in the tumor microenvironment are detected and early evaluation of response to therapy such as tumor attenuation/enhancement, perfusion, oxygenation, metabolism, etc., are possible. 


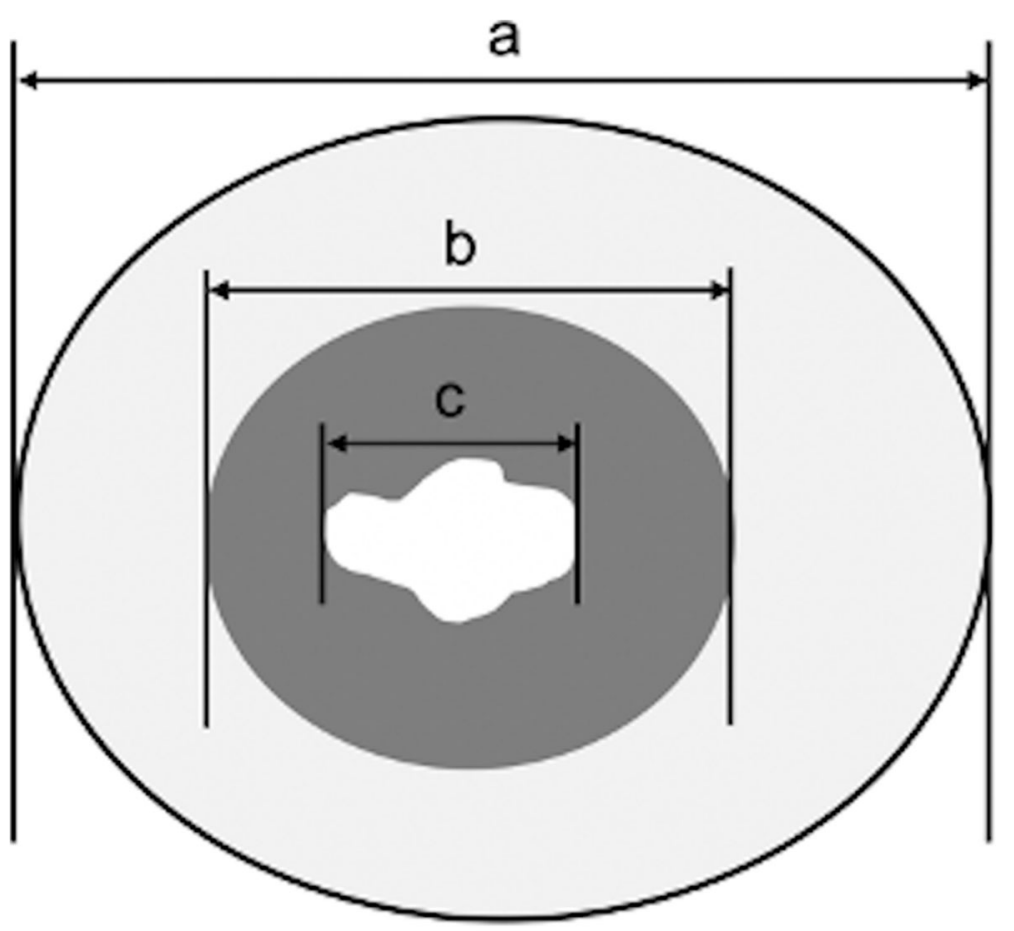

- RECIST measurement: a

- Lee's measurement: b - c

Fig. 5 Illustration depicting the target lesion measurement in NSCLC by RECIST and Lee's criteria. According to RECIST criteria, the size of the target lesion in lung cancer is measured by including both solid and ground-glass opacity (GGO) components (a). According to Lee's criteria, the size of the target lesion is measured by solid component alone on soft tissue window imaging (b). If the target lesion has intratumoral cavitation, the size of the target lesion is measured by including only the soft-tissue component and excluding the air component (subtraction of cavity diameter from the longest diameter of tumor mass) (b - c)

\section{Evaluation of tumor attenuation/enhancement}

Tumor enhancement/attenuation changes in CT are important imaging biomarkers for the assessment of tumor responses $[22,47,48]$. In patients receiving molecular targeting agents, a decrease of tumor attenuation on CT indicates a response to therapy, even in the absence of decreased tumor size as defined by RECIST. In contrast, tumor progression may demonstrate patterns of new intratumoral enhancing lesions rather than tumor size increase. Choi criteria [22] (Table 7) were the first to introduce this CT parameter for evaluating the effect of imatinib mesylate (Gleevec), a TKI, in gastrointestinal stromal tumors (GIST). For malignant GISTs, early dramatic changes in the extent of tumor attenuation are often observed after using imatinib (Fig. 7) [49]. However, morphological changes in unmodified RECIST alone may not be sufficient to estimate the effect of imatinib in GISTs, especially at an early stage of treatment that are poor predictors of clinical benefit. Choi criteria define a good response by a $10 \%$ decrease in tumor size or a $15 \%$ decrease in CT attenuation (Table 7). Choi criteria also define PD by the (1) appearance of new lesions, (2) appearance or increase in the size of intratumoral nodules, or (3) tumor size increase by more than $20 \%$ without post-treatment hypoattenuation change.

Similar phenomena were observed in other solid tumors, including HCC, colorectal liver metastases, renal cell carcinomas (RCC), and sarcomas [22, 47, 48]. In 2000, the EASL agreed that estimating the reduction in viable tumor volume (recognized as poorly-enhanced areas on dynamic CT or MRI) should be considered for locoregional therapies such as trans-arterial chemoembolization (TACE) or radiofrequency ablation (RFA) in HCC [9]. In HCC, several studies showed a poor correlation between the clinical benefits and conventional response criteria in treatments by sorafenib and locoregional therapies such as TACE or RFA [50,51]. Therefore, a modified RECIST (mRECIST) was described by Lencioni et al. [16] in 2010. The mRECIST for HCC was developed based on the concept that a viable tumor is defined as showing intratumoral arterial enhancement by contrast agent during dynamic CT or MRI (Fig. 1) [9]. Therefore, measurement of tumor enhancement can be used 


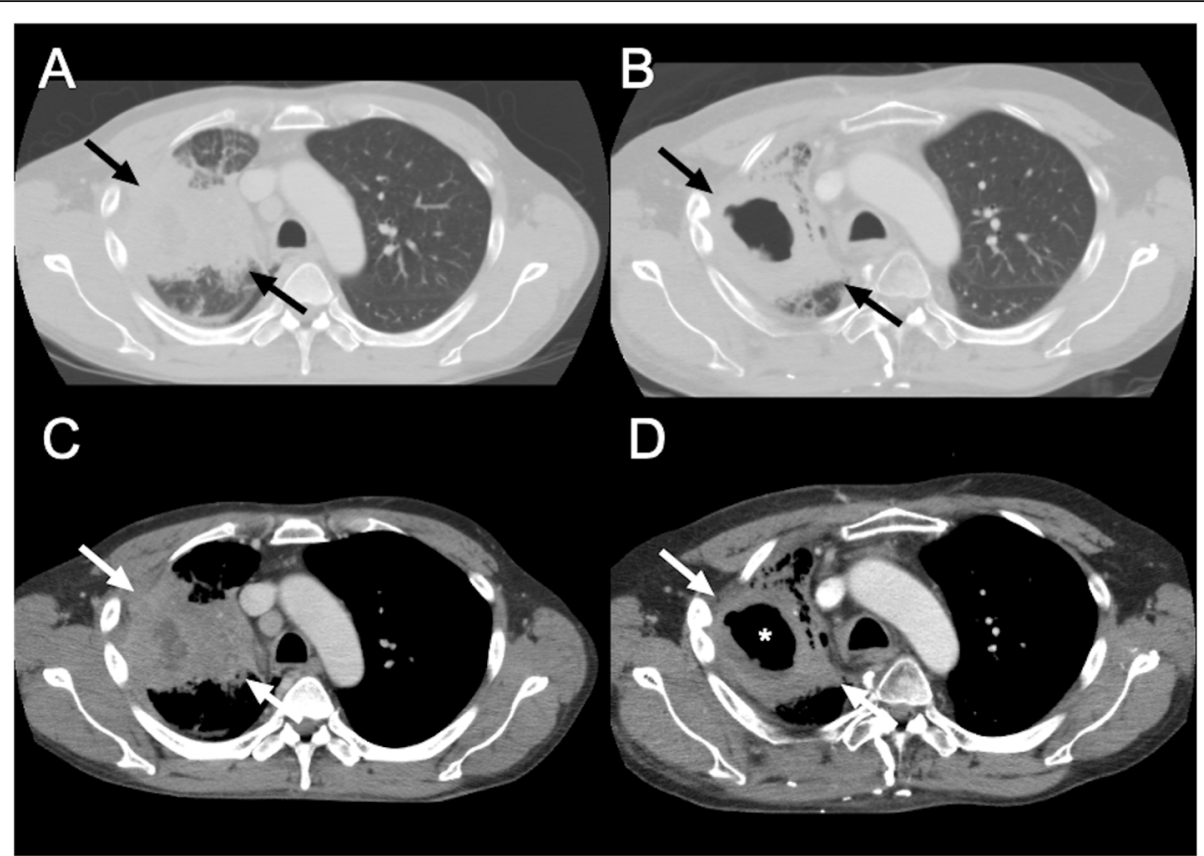

Fig. 6 Comparison between RECIST and Lee's criteria in NSCLC. A 51-year-old man was diagnosed with NSCLC. A Pretreatment CE axial CT scan in lung window shows a 92-mm-sized tumor, including both solid and GGO components (black arrows). B After targeted therapy with afatinib, posttreatment CE CT scan shows no significant decrease in tumor size ( $84 \mathrm{~mm}$ in diameter, $9 \%$ reduction) (black arrows), suggesting stable disease according to RECIST 1.1. C According to Lee's criteria, the size of the target lesion (white arrows) is measured on pretreatment CE axial CT by solid component alone (79 $\mathrm{mm}$ in diameter) on soft tissue window imaging. $\mathbf{D}$ After targeted therapy, the size of the target lesion is measured by including only soft-tissue tumor (white arrows) $(77 \mathrm{~mm}$ in diameter) and excluding necrotic air cavitation (asterisk) (49 mm in diameter), thus the tumor size is $28 \mathrm{~mm}$ ( $65 \%$ reduction), suggesting good tumor response according to Lee's criteria

as a surrogate biomarker of a viable tumor. Furthermore, tumor necrosis induced by treatments should be considered as a response assessment. Besides, for patients with colorectal liver metastasis, tumor attenuation correlates well with survival rate after bevacizumab treatment, whereas RECIST criteria do not correlate with patient survival [52]. For metastatic RCC treated with sunitinib, the Choi criteria also had a better predictive value than RECIST in defining patients who benefit from therapy [53].

\section{$C T$ and MRI perfusion imaging}

The basis for using CT and MRI perfusion in oncology is that the microvascular changes of angiogenesis are reflected by neovascularization in tumor cells [54]. These techniques can quantify regional tumor blood flow (BF), tumor blood volume (BV), micro-vessel permeability, contrast medium extraction fraction, and extraction fraction on plasma and interstitial volumes. Clinical applications of CT and MRI perfusion include lesion characterization, tumor staging, predicting therapeutic response and clinical outcome, and evaluation of tumor relapse and drug resistance [55].

The degree of CT perfusion is related to tumor aggressiveness in many types of cancer, and highly vascularized tumors are associated with a poor prognosis [54, 56, 57]. Higher baseline BF on CT perfusion predicts better response to chemotherapy and radiotherapy in different tumors. Bellomi et al. [58] reported that patients with

Table 6 Positron Emission Tomography Response Criteria in Solid Tumors (PERCIST)

\begin{tabular}{ll}
\hline Response & Criteria \\
\hline CR & $\cdot$ Disappearance of all metabolically active tumor \\
PR & $\cdot>30 \%$ decrease in SUL peak (minimum 0.8 unit decrease) in lesion with greatest uptake (not necessarily the same lesion) \\
PD & $\cdot>30 \%$ increase in SUL peak (minimum 0.8 unit increase) \\
& $\cdot>75 \%$ increase in total lesion glycolysis \\
SD & New lesions \\
\hline$C$
\end{tabular}

$C R$ complete metabolic response, $P D$ progressive metabolic disease, $P R$ partial metabolic response, $S D$ stable metabolic disease, $S U L$ standardized uptake value using lean body mass 
Table 7 Choi Criteria

\begin{tabular}{|c|c|}
\hline Response & Criteria \\
\hline$\overline{C R}$ & $\begin{array}{l}\text { - Disappearance of all lesions } \\
\text { - No new lesions }\end{array}$ \\
\hline PR & $\begin{array}{l}\text { - A decrease in tumor size } \geq 10 \% \text { or a decreased in tumor attenuation (Hounsfield unit) } \geq 15 \% \text { on CT } \\
\text { - No new lesions } \\
\text { - No obvious progression of non-measurable disease }\end{array}$ \\
\hline PD & $\begin{array}{l}\text { - An increase in tumor size } \geq 10 \% \text { and does not meet criteria of PR by tumor attenuation on CT } \\
\text { - New lesions } \\
\text { - New intratumoral nodules or increase in size of the existing intratumoral nodules }\end{array}$ \\
\hline SD & $\begin{array}{l}\text { - Does not meet criteria of } \mathrm{CR}, \mathrm{PR} \text {, or } \mathrm{PD} \\
\text { - No symptomatic deterioration resulted from tumor progression }\end{array}$ \\
\hline
\end{tabular}

$C R$ complete response, $P D$ progressive disease, $P R$ partial response, $S D$ stable disease

higher baseline BF and BV had better responses in rectal carcinoma. In squamous cell carcinoma of the head and neck, Hermans et al. [59] showed that lower CT perfusion values had a significantly higher local failure rate. Hypervascular tumors allow delivery of chemotherapy and may have more oxygenation for greater radiosensitivity [60,61]. Different antiangiogenic agents such as antibodies targeting vascular endothelial growth factor (VEGF) and small-molecule TKIs have been developed $[57,62]$. Higher pretreatment CT perfusion values are associated with a better response rate to antiangiogenic drugs $[63,64]$. As compared to RECIST and tumor attenuation, Jiang et al. [65] proposed that CT perfusion is a more sensitive imaging biomarker in advanced HCC patients treated with a combination of anti-angiogenic and conventional chemotherapies.

MRI perfusion also has the ability to analyze underlying tumor angiogenesis by parameters related to tumor perfusion and permeability after the intravenous injection of gadolinium-based contrast agents [66]. Depending on the technique utilized, MRI perfusion can provide information about tissue cerebral blood volume and perfusion (using dynamic susceptibility contrastenhanced [DSC] MRI), or micro-vessel permeability and the extracellular space (using T1-weighted dynamic contrast-enhanced [DCE] MRI). DSC-MRI is usually used for the evaluation of brain tumors, and the most commonly calculated parameters are relative cerebral blood volume (rCBV), relative cerebral blood flow $(\mathrm{rCBF})$, and mean transit time (MTT). Pharmacokinetic analysis of DCE-MRI is the most widely used method for the quantitative measurement of vessel permeability changes (Fig. 8). With the Tofts model [67], an evaluation of the injected contrast agent leaking into the extravascular-extracellular space, and tissue perfusion and permeability becomes possible. The volume transfer constant $\mathrm{K}^{\text {trans }}$ (wash-in rate; unit: $\mathrm{min}^{-1}$ ) describes the forward leakage rate of the contrast medium. For blood vessels where the leakage is rapid, perfusion determines the contrast agent distribution and $K^{\text {trans }}$ is similar to tissue blood flow per unit volume [68]. This is typically reported in breast tumors where the endothelium is leaky and other high permeability situations and is termed a flow-limited situation. For the prediction of therapeutic

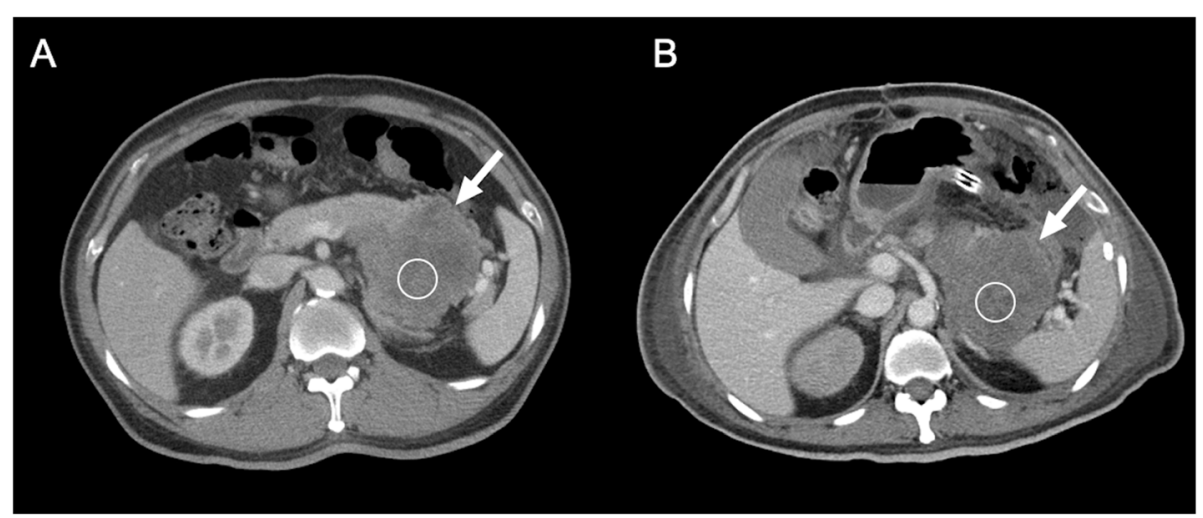

Fig. 7 Application of Choi criteria in the gastrointestinal stromal tumor (GIST) after targeted therapy with imatinib. A 49-year-old man was diagnosed with GIST. A Pretreatment CE axial CT scan shows an 88-mm-sized enhancing tumor (arrow) arising from the stomach. The measured CT number on the region of interest (ROI) is 36.1 Hounsfield units ( $\mathrm{HU})$. B After targeted therapy with imatinib, posttreatment CE CT scan shows no significantly decreased in tumor size ( $87 \mathrm{~mm}$ in diameter) (arrow) but markedly decreased attenuation (22.6 HU, $37 \%$ reduction), suggesting tumor response according to Choi criteria 


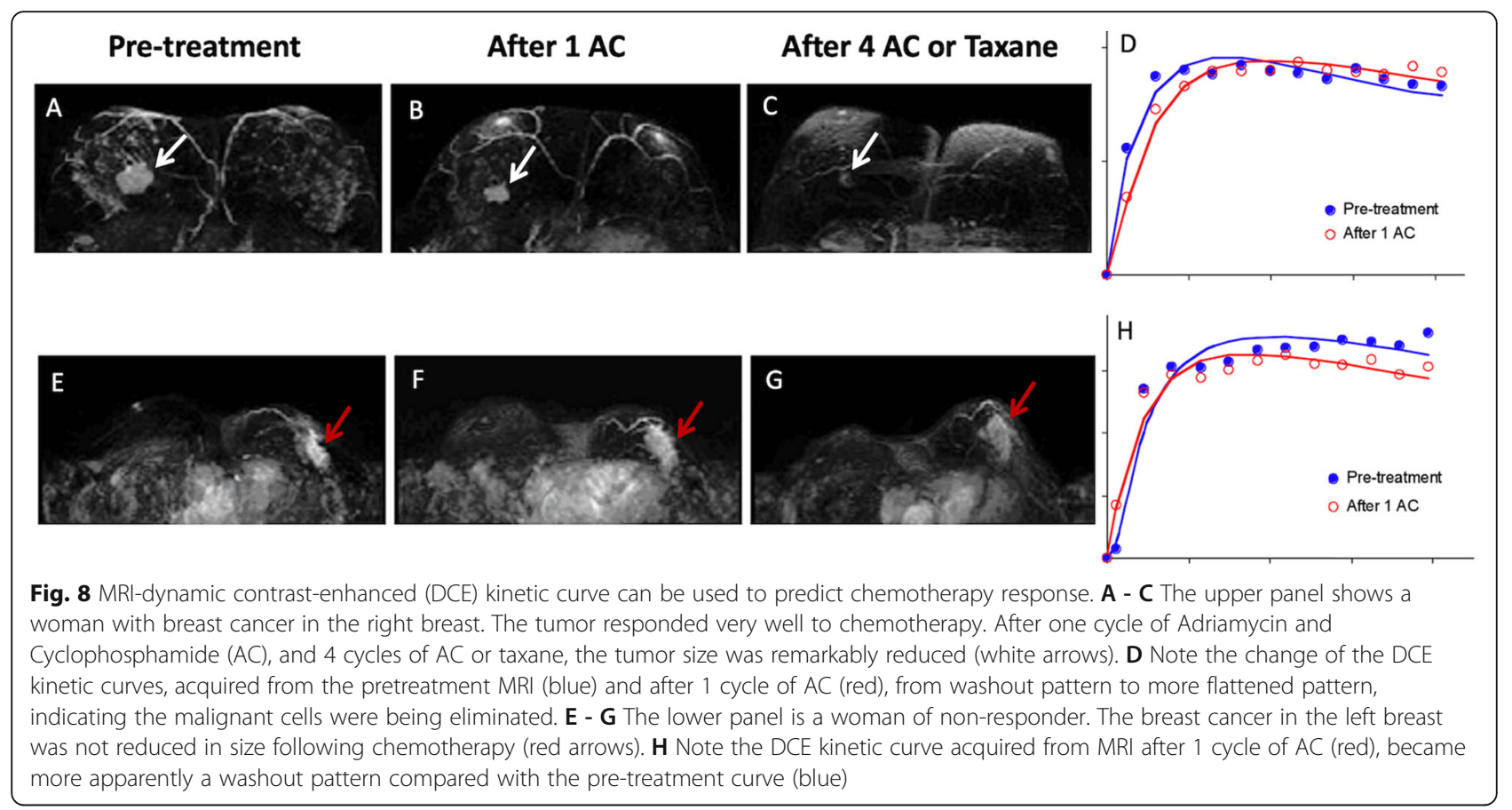

efficacy in tumors, both blood perfusion and microvessel permeability are important determinants [69]. Morabito et al. [69] reported that both blood perfusion (rCBV) and micro-vessel permeability $\left(\mathrm{K}^{\text {trans }}\right)$ are useful tools for differentiating tumor recurrence from radiation necrosis in brain tumors. Quantitative assessment of contrast enhancement kinetic curve on breast DCE-MRI resulted in excellent diagnostic performance for differentiation of malignancy (Fig. 8) [70]. Wedam et al. [71] reported that DCE-MRI parameters including $\mathrm{K}^{\text {trans }}$, kep (reverse rate constant from tumor to the vascular space), and ve (extravascular volume fraction) could be used as an early imaging biomarker for monitoring treatment response in breast cancer patients receiving bevacizumab. Other cancers that can be monitored by DCE-MRI include radiotherapy in rectal cancer [72], metastatic renal cell carcinoma treated with sorafenib [73], androgen withdrawal therapy in prostate cancer [74], and radiofrequency ablation in HCC [75]. It is known that successful treatment usually leads to decreases in $\mathrm{BF}$ and permeability in assessing response to chemotherapy, radiotherapy, and anti-angiogenic therapy [76].

\section{Diffusion-weighted MR imaging (DWI)}

The consensus concerning DWI as a cancer imaging biomarker was reached in 2008 at the International Society for Magnetic Resonance in Medicine Meeting [77]. Therefore, DWI has been widely used as an imaging biomarker in the characterization of malignancy, determination of lesion aggressiveness, and monitoring response to a variety of treatments [77-79]. In theory, DWI provides biomedical information related to tissues and structures of interest-based on the measurement of thermally induced "Brownian motion" of water molecules shown by apparent diffusion coefficient (ADC) value [80]. The information provided by DWI includes tissue perfusion, cellularity, extracellular space distribution, and the integrity of cell membranes. Thus, unusual imaging findings on DWI could be an early predictor of biophysiological abnormality [77]. In oncologic imaging, DWI has been linked to tumor aggressiveness and treatment response [77]. Parameters derived from DWI are appealing as imaging biomarkers because the acquisition is rapid and noninvasive, requiring no exogenous contrast agents or exposure to ionizing radiation.

In oncologic practice, the measurements of water diffusivity are used as biomarkers of tissue properties. Since tissue water movements are not "free" but impeded by cells, extracellular matrix, and other molecules, the measurement of tissue water diffusivity is often termed the ADC value. The biomarkers used in oncology include relative signal intensity at different b-values, water diffusivity $(\mathrm{D})$, perfusion fraction $\left(\mathrm{F}_{\mathrm{p}}\right), \mathrm{ADC}_{\text {total }}$, fractionated $\mathrm{ADC}\left(\mathrm{ADC}_{\text {fast }}\right.$ and $\left.\mathrm{ADC}_{\text {slow }}\right)$, and fractional anisotropy (FA) [81]. $F_{p}$ represents the contribution of blood microcirculation and microscopic flow to signal decay. $\mathrm{ADC}_{\text {fast }}$ is calculated using low b-values $\left(0-100 \mathrm{~s} / \mathrm{mm}^{2}\right)$ and is dominated by this perfusion component of the total tissue diffusivity. At higher b-values $\left(>100 \mathrm{~s} / \mathrm{mm}^{2}\right)$, the perfusion component is largely extinguished, so $\mathrm{ADC}_{\text {slow }}$ measurements are more heavily determined by water diffusion within the cellular matrix. For most 
clinical studies, only $\mathrm{ADC}_{\text {total }}$ is reported, which is the total ADC including perfusion contributions. In the above discussion, it is assumed that water movements in tissues are nondirectional (isotropic). However, in some tissue such as brain white matter and renal tubules, water mobility in normal tissues can be directional (anisotropic). A commonly used measurement of anisotropy is $\mathrm{FA}$, which is a dimensionless quantity with range between 0 (nondirectional, isotropic) to 1 (highly directional, anisotropic) [82].

The DWI offers useful clinical information at all stages of cancer, including detection, diagnosis, staging, monitoring therapy response, assessing recurrence, and developing pharmaceutical drugs [77]. The applications of DWI as an early biomarker for the prediction of treatment outcomes in different tumors such as brain glioblastoma, hepatic tumor, lung cancer, and primary bone sarcomas had been reported (Fig. 9) [83-87]. Pretreatment low ADC values correlate with poor survival in malignant brain astrocytomas independent of tumor grade (Fig. 9) [88]. Higher pretreatment ADC values were associated with better therapeutic response in vascular disruptive agents [89]. In contrast, several clinical studies have noted that higher pretreatment $\mathrm{ADC}$ values respond less favorably to treatments [90-92], reflecting the presence of microscopic and macroscopic necrosis, which is recognized to be associated with poorer therapeutic outcomes [93]. Association between necrosis and hypoxia in tumors is probably involved. Hypoxia in tumor cells mediates resistance to chemotherapy, radiation, and photodynamic therapy [93]. The association between higher pretreatment $\mathrm{ADC}$ values and the poorer response had been reported in rectal cancer, liver metastasis, and breast cancers [94-96]. Furthermore, successful treatment is reflected by increased $A D C$ values in several different tumors, including breast cancer, HCC, malignant brain tumors, and primary bone sarcomas [97-100].

\section{Magnetic Resonance Spectroscopy (MRS)}

The alterations in metabolite levels are best detected both noninvasively and quantitatively by MRS. Although MRS is usually applied in brain lesions, it can also be used for detection, staging, evaluation of aggressiveness, and assessment of therapeutic response in the breast, prostate, hepatic, and other cancers [46]. MRS can be procured from several nuclei in the body, such as 1Hydrogen (1 H), 31-Phosphorus, and 19-Fluorine. Typically, $1 \mathrm{H}$-MRS is the most common clinically used method because of the high sensitivity to this nucleus,

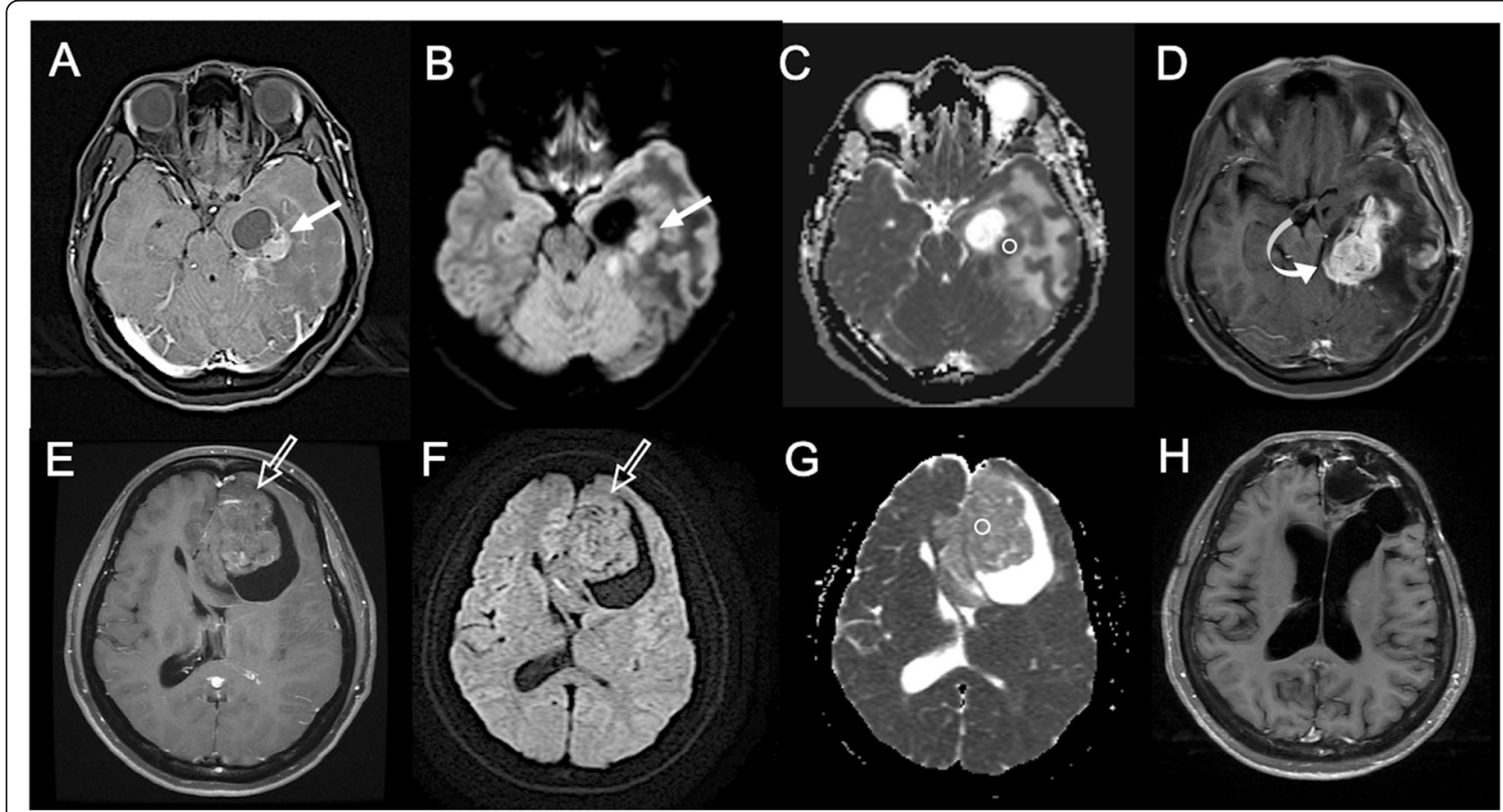

Fig. 9 Low apparent diffusion coefficient (ADC) value on diffusion-weighted imaging (DWI) can predict worse therapeutic response in brain glioblastoma. A Pretreatment CE axial T1-weighted imaging (T1WI) shows a 40-mm-sized enhancing glioblastoma (arrow) with the cystic component in the left temporal lobe. B The DWI shows hyperintensity in the solid part of the tumor (arrow), indicating a diffusion restriction phenomenon. C The measured ADC value $\left(b=1000 \mathrm{~s} / \mathrm{mm}^{2}\right)$ on $\mathrm{ROI}$ is $0.72 \times 10^{-3} \mathrm{~mm}^{2} / \mathrm{sec}$. (D) Rapid tumor recurrence (tumor diameter of 54 $\mathrm{mm}$ ) (curved arrow) was observed 3 months after surgical resection. E Pretreatment CE axial T1WI shows another 65-mm-sized enhancing glioblastoma (open arrow) with a cystic component in the left frontal lobe. $\mathbf{F}$ DWI shows isointensity (no diffusion restriction) in the solid part of the tumor (open arrow). G The measured ADC value on $\mathrm{ROI}$ is $1.42 \times 10^{-3} \mathrm{~mm}^{2} / \mathrm{sec}$. (H) No tumor recurrence was observed 72 months after surgical resection 
easy accessibility, and the abundant existence of hydrogen in metabolites. MRS procedure begins with the acquisition of MR images and then assesses the "metabolite spectrum" in the region of interest. In single voxel spectroscopy (SVS), a single voxel (volume of tissue) is located in the tumor or lesion where the metabolism may be damaged as a result of patient disease. Another technique of MRS is known as chemical shift imaging (CSI) [101]. In CSI, a large volume divided into several smaller voxels is selected to produce all voxel's spectrum simultaneously. Usually, SVS is the preferred choice when accurate quantification is required, and CSI is used to provide an overall vision of spatial distributions of the metabolite $[102,103]$.

In brain tissue, $\mathrm{N}$-acetyl aspartate (NAA), creatine (Cr), and choline (Cho) are the most important metabolites as an MRS signal [104]. The derivatives of $\mathrm{Cr}$ form an important system for energy metabolism, and their intensity is considered fixed. Therefore, they are applied in the computing of metabolite ratios. Brain tumors commonly cause an increase in Cho concentration. Cho level is related to the ability of proliferation and existence of malignancy, and an increased Cho signal is a marker of the presence of a brain tumor [105]. In contrast to Cho, the signal of NAA, which is a neuronal marker, typically decreases in brain tumors. Since the level of Cho and NAA signal changes in brain tumors, the calculation of this Cho-NAA ratio is helpful in the interpretation of brain tumor's MRSI spectra [106]. The anaerobic metabolism in tumor cells also causes the appearance of lactate peak in the brain tumor's spectra. The increase in lactate and lipid peaks are the markers of tumor progression and transformation from a lowgrade to a high-grade tumor [107].

For breast cancer, Roebuck et al. [108] first proposed that the Cho peak can be applied as a sign of malignancy (Fig. 10). Several studies also showed that Cho peak is a useful marker in malignant breast lesions, and it is not visible in normal tissues or benign tumors $[109,110]$. Further, Jagannathan et al. [111] first reported the Cho peak is diminished in $89 \%$ of cases that underwent chemotherapy. These promising results suggest that MRS increases the sensitivity, specificity, and accuracy of breast MRI and will be a useful tool in the diagnosis and management of breast cancer [112]. In prostate cancer, CSI of MRS has shown that it has high diagnostic accuracy [113]. The MRS gathers metabolic information of prostatic tissue by calculating the relative concentrations of citrate, $\mathrm{Cr}$, and Cho. Further, prostate adenocarcinoma can be differentiated from normal adjacent tissue based on the $(\mathrm{Cho}+\mathrm{Cr}) /$ citrate ratio with a cut-off value of $0.8[114,115]$. H1-MRS can also be applied in the diagnosis of gastrointestinal tumors and malignant ovarian tumors $[116,117]$. These results revealed that most cancer lesions can be determined by the increase of Cho and lactate peaks with a decrease of lipid peak [118].
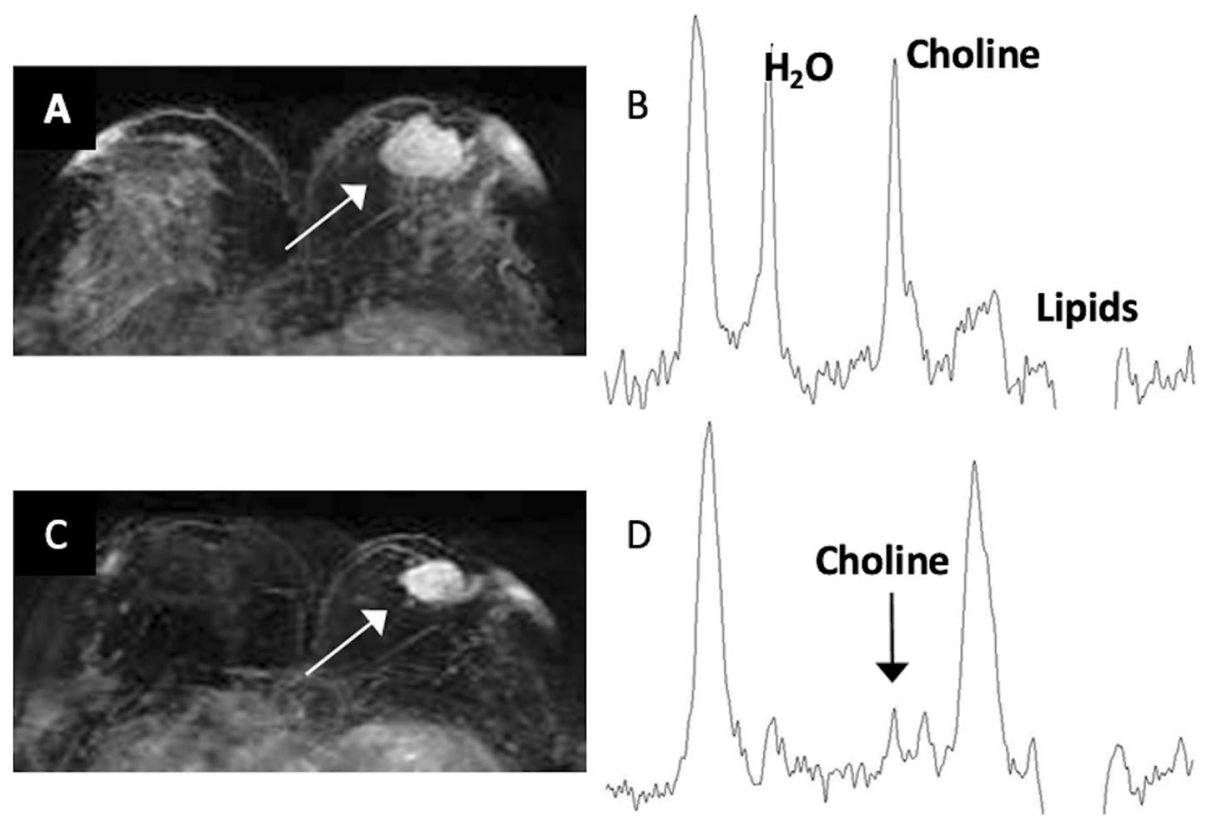

Fig. 10 Proton magnetic resonance spectroscopy (MRS) can early predict chemotherapy response. A A woman with $34 \mathrm{~mm}$ breast cancer in the left breast (white arrow). B The pretreatment MRS shows a choline peak of $2.33 \mathrm{mmol} / \mathrm{kg}$. C After one cycle of Adriamycin and Cyclophosphamide, the tumor was $26 \mathrm{~mm}$ (white arrow), showing a $24 \%$ reduction in size. According to the RECIST 1.1, this is a non-responder D However, posttreatment MRS shows much more sensitive evidence of tumor response with a $51 \%$ reduction of total choline level (from 2.33 $\mathrm{mmol} / \mathrm{kg}$ to $1.15 \mathrm{mmol} / \mathrm{kg}$ ) (black arrow) 


\section{Metabolic imaging}

For newer anti-cancer therapies that stabilize disease rather than reduce tumor size at the beginning of treatments, the ${ }^{18}$ F-FDG PET offers particularly valuable information in these cases. PET can assess tissue metabolism by using radiolabeled molecules, most commonly ${ }^{18}$ F-FDG, a glucose analog. ${ }^{18}$ F-FDG PET-CT or MRI is of value in the differentiation of benign and malignant tissues, preoperative staging, recurrent disease detection, and identification of early tumor response to therapy. Wahl et al. [24] proposed guidelines for the standardization of response criteria for FDG PET, the so-called PERCIST criteria (Table 6). The standardized uptake value (SUV) normalized by lean body mass (SUL) represents a quantitative assessment of uptake in a tumor region of interest. The SUV/SUL is based on a ratio between tracer uptake within a tumor and homogeneous distribution of tracer within the patient body. By reflecting the change in tumor metabolism, ${ }^{18}$ F-FDG PET establishes a method to measure tumor response in the absence of marked anatomic changes (Fig. 11) [119]. A decrease in FDG uptake indicates treatment response or improves survival rates in patients with solid tumors such as breast cancer [120], esophageal cancer [121], lung cancer [122, 123], osteosarcoma [124], and other tumors [125].

${ }^{18}$ F-FDG PET provides more rapid response data than morphological measurements [126, 127]. In patients with NSCLC, ${ }^{18}$ F-FDG PET is a staging tool, and the SUV provides prognosis before and after the treatment [122, 123]. It prevented futile thoracotomies in lung cancer [128] and stratified patients into surgical versus palliative groups in colorectal cancer [129]. However, the SUV changes are also influenced by other factors such as vascular delivery. In primary breast tumors, a reliable dropin SUVs indicating a tumor response is seen only for patients with high initial SUVs [130]. Therefore, a reduction in PET metabolism caused by chemotherapy may be dependent on pre-therapy vascular delivery [131].

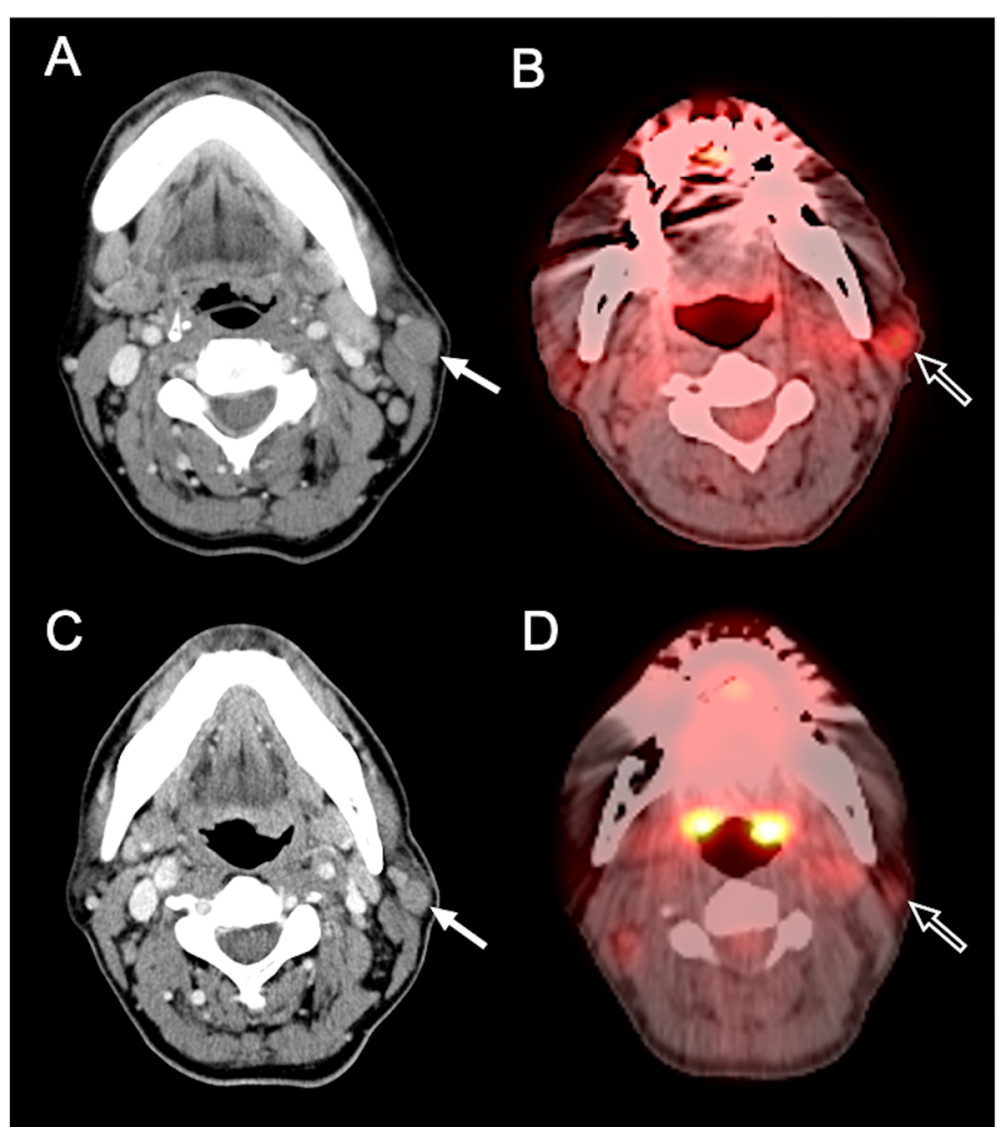

Fig. $11^{18}$ F-fluorodeoxyglucose (FDG) positron emission tomography (PET) can predict early response in targeted therapy. A 53-year-old man was diagnosed with Hodgkin lymphoma at the left parotid gland. A Pretreatment CE axial CT imaging shows a 16 mm tumor mass at the left parotid gland (white arrow). B The SUVmax value of 3.0 in the target lesion (open arrow) was detected on a pretreatment PET-CT scan. C After five cycles of brentuximab vedotin, a tumor size of $13.5 \mathrm{~mm}$ (white arrow) was observed, showing a $16 \%$ reduction in size. According to the RECl ST 1.1, this is a non-responder. D However, posttreatment PET-CT scan shows good tumor response with $50 \%$ reduction of SUVmax value (from 3.0 to 1.5 ) (open arrow) 


\section{Radiomics approach}

Radiomics is a possible exciting complement to RECIST for monitoring and predicting therapeutic response. Both $\mathrm{CT}$ and MRI radiomics analysis are new field in medical imaging. This approach is based on computerized extraction of several quantitative imaging features, and uses these data for the medical decision, prediction, and monitoring response to therapy [132]. A general pipeline of radiomics analysis includes feature extraction, feature selection, and prediction. Feature extraction quantitatively defines the imaging parameters from the specified areas of the images. Feature selection evaluates the feature importance based on the objectives, and the prediction model is established by selected features [132]. Radiomics extracts a large number of quantitative imaging features from a medical image and then analyses these features by a series of machine learning algorithms. The extracted imaging features are related to the underlying anatomical microstructure and biophysical processes such as genetic expression, tumor proliferation, and tumor neovascularization [133]. Radiomics in texture and shape analysis had been widely used to evaluate medical images with promising results $[134,135]$. Recently, radiomics analysis is emerging as a comprehensive quantitative method to diagnose and evaluate response to therapy in brain tumors, head and neck cancer, breast cancer, liver tumor, prostate cancer, rectal cancer, non-small-cell lung cancer, and metastatic RCC [136-143]. With radiomics, texture analysis reveals visually imperceptible information that extends beyond radiology to histopathology and provides predictors for diagnosis, prognosis, and therapeutic planning for cancer patients [136-139].

Radiomics is especially a possible useful tool to predict response to radiation therapy, different chemotherapies, and immune checkpoint inhibition treatments, especially in lung cancer $[144,145]$. It can be potentially integrated into the normal clinical workflow to identify lung cancer patients who would benefit most from therapy [144]. Huynh et al. [145] reported that CT-based radiomic shape and tumor heterogeneity features could predict the treatment response to stereotactic body radiation therapy in early-stage NSCLC. In locally advanced NSCL C, Rakshit et al. [146] showed that certain textural features are radiomics predictors for response to pemetrexed chemotherapy, with an AUC of 0.81 . Velcheti et al. [147] developed a pretherapy CT radiomics-based predictive model for the prediction of tumor response to Nivolumab in locally advanced NSCLC, with an AUC of 0.84 . Other studies applying radiomics on NSCLC also showed very positive and promising results $[148,149]$.

\section{Conclusions}

Conventionally, tumor response is evaluated basically and readily by the use of RECIST 1.1. However, the criteria mainly focus on tumor dimensional changes and do not reflect other functional, metabolic, and nonmorphological changes that may occur in moleculartargeted therapy, immunotherapy, and local treatments. Since morphological changes in unmodified RECIST 1.1 alone may not be sufficient to estimate the treatment response in cancer patients, several modified criteria have been proposed to improve the response assessment in different specific tumors. Due to the rapid progress in anti-cancer therapies nowadays, the new imaging techniques such as CT/MRI-based perfusion, DWI, MRS, PET, and radiomics should be recognized by radiologists and oncologists for tumor response evaluation. On the other hand, although imaging is utilized for evaluating tumor response in daily oncological practice, the situation in which imaging is used differs to some degree between clinical trials and routine clinical practice [150]. The challenges of standardizing imaging in the multicenter clinical trials include the processes of image acquisition, data analysis, and radiological review [150]. The emergence of new treatment paradigms and the trend toward personalized treatment should be accompanied by the evolution of response assessment. Although these new imaging techniques make clinically effective contributions to cancer care as a decisionmaking method for personalized medicine [151], it may be cost prohibitive and challenging to implement in some institutions at this moment. To resolve this problem, the aim toward developing more affordable and effective alternatives is necessary. In our opinion, integrating multiparametric quantitative information from different imaging modalities for precise personalized medicine and evaluation is the goal of cancer treatment in the future

\section{Abbreviations}

RECIST: Response Evaluation Criteria in Solid Tumors; CT: Computed tomography; MRI: Magnetic resonance imaging; DWI: Diffusion-weight MR imaging; MRS: Magnetic resonance spectroscopy; FDG: ${ }^{18} \mathrm{~F}-$

fluorodeoxyglucose; PET: Positron emission tomography; WHO: World Health Organization; HCC: Hepatocellular carcinoma; MPM: Malignant pleural mesothelioma; DCE: Dynamic contrast-enhanced; PD: Progressive disease; EASL: European Association for the Study of the Liver; RECICL: Response Evaluation Criteria in Cancer of the Liver; RANO: Response Assessment in Neuro-Oncology; FLAIR: Fluid-attenuated inversion recovery; MDA: MD Anderson; NSCLC: Non-small cell lung cancer; anti-PD-1: Anti-programmed cell death protein-1; anti-PD-L1: Anti-programmed death-ligand 1; anti-CTLA4: Anti-cytotoxic T lymphocyte-associated antigen 4; GGO: Ground-glass opacity; EGFR: Epidermal growth factor receptor; TKI: Tyrosine kinase inhibitor; PERCIST: Positron Emission Tomography Response Criteria in Solid Tumors; GIST: Gastrointestinal stromal tumors; RCC: Renal cell carcinoma; TACE: Trans-arterial chemoembolization; RFA: Radiofrequency ablation; mRECIST: Modified RECIST; BF: Blood flow; BV: Blood volume; VEGF: Vascular endothelial growth factor; DSC: Dynamic susceptibility contrast-enhanced; rCBV: Relative cerebral blood volume; rCBF: Relative cerebral blood flow; MTT: Mean transit time; ADC: Apparent diffusion coefficient; $F_{p}$ : Perfusion fraction; FA: Fractional anisotropy; SVS: Single voxel spectroscopy; CSI: Chemical shift imaging; NAA: N-acetyl aspartate; Cr: Creatine; Cho: Choline; SUV: Standardized uptake value; SUL: Standardized uptake value normalized by lean body mass 


\section{Supplementary Information}

The online version contains supplementary material available at https://doi. org/10.1186/s40364-021-00306-8

\section{Additional file 1.}

\section{Acknowledgements}

None.

\section{Authors' contributions}

Conceived and designed the study: CCK JHC. Analyzed the data: CCK JHC. Contributed reagents/materials/analysis tools: LRY YTK. Wrote the paper: CCK. Critically revised the article: JHC. The author(s) read and approved the final manuscript.

\section{Funding}

The authors received no specific funding for this work.

\section{Availability of data and materials}

The datasets used during the current study are available from the corresponding author on reasonable request.

\section{Declarations}

\section{Ethics approval and consent to participate}

Not applicable.

\section{Consent for publication}

Not applicable.

\section{Competing interests}

The authors declare that they have no competing interests.

\section{Author details}

${ }^{1}$ Department of Medical Imaging, Chi Mei Medical Center, Tainan, Taiwan. ${ }^{2}$ Department of Health and Nutrition, Chia Nan University of Pharmacy and Science, Tainan, Taiwan. ${ }^{3}$ Department of Radiology, E-DA Hospital, I-Shou University, Kaohsiung, Taiwan. ${ }^{4}$ Department of Medical Imaging, Kaohsiung Medical University Hospital, Kaohsiung, Taiwan. ${ }^{5}$ Tu \& Yuan Center for Functional Onco-Imaging, Department of Radiological Sciences, University of California, 164 Irvine Hall, Irvine, CA 92697 - 5020, USA.

Received: 15 December 2020 Accepted: 10 June 2021 Published online: 02 July 2021

\section{References}

1. O'Connor JP, Aboagye EO, Adams JE, Aerts HJ, Barrington SF, Beer AJ, et al. Imaging biomarker roadmap for cancer studies. Nat Rev Clin Oncol. 2017; 14(3):169-86.

2. Wang YX, Deng M. Medical imaging in new drug clinical development. J Thorac Dis. 2010;2(4):245-52.

3. Therasse P, Arbuck SG, Eisenhauer EA, Wanders J, Kaplan RS, Rubinstein L, et al. New guidelines to evaluate the response to treatment in solid tumors. European Organization for Research and Treatment of Cancer, National Cancer Institute of the United States, National Cancer Institute of Canada. J Natl Cancer Inst. 2000;92(3):205-16.

4. Eisenhauer EA, Therasse P, Bogaerts J, Schwartz LH, Sargent D, Ford R, et al. New response evaluation criteria in solid tumours: revised RECIST guideline (version 1.1). Eur J Cancer. 2009;45(2):228-47.

5. Saini S. Radiologic measurement of tumor size in clinical trials: past, present, and future. AJR American journal of roentgenology. 2001;176(2):333-4.

6. Ratain MJ, Eckhardt SG. Phase II studies of modern drugs directed against new targets: if you are fazed, too, then resist RECIST. J Clin Oncol. 2004; 22(22):4442-5.

7. Rosner GL, Stadler W, Ratain MJ. Randomized discontinuation design: application to cytostatic antineoplastic agents. J Clin Oncol. 2002;20(22): 4478-84.

8. $\quad$ Kang H, Lee HY, Lee KS, Kim JH. Imaging-based tumor treatment response evaluation: review of conventional, new, and emerging concepts. Korean J Radiol. 2012;13(4):371-90.
9. Bruix J, Sherman M, Llovet JM, Beaugrand M, Lencioni R, Burroughs AK, et al. Clinical management of hepatocellular carcinoma. Conclusions of the Barcelona-2000 EASL conference. European Association for the Study of the Liver. J Hepatol. 2001;35(3):421 - 30.

10. Scher HI, Morris MJ, Kelly WK, Schwartz LH, Heller G. Prostate cancer clinical trial end points: "RECIST"ing a step backwards. Clin Cancer Res. 2005;11(14): 5223-32.

11. Chukwueke UN, Wen PY. Use of the Response Assessment in NeuroOncology (RANO) criteria in clinical trials and clinical practice. CNS Oncol. 2019;8(1):CNS28-CNS.

12. Costelloe CM, Chuang HH, Madewell JE, Ueno NT. Cancer Response Criteria and Bone Metastases: RECIST 1.1, MDA and PERCIST. J Cancer. 2010;1:80-92.

13. Byrne MJ, Nowak AK. Modified RECIST criteria for assessment of response in malignant pleural mesothelioma. Ann Oncol. 2004;15(2):257-60.

14. Barnacle AM, McHugh K. Limitations with the response evaluation criteria in solid tumors (RECIST) guidance in disseminated pediatric malignancy. Pediatr Blood Cancer. 2006;46(2):127-34.

15. Subbiah V, Chuang HH, Gambhire D, Kairemo K. Defining Clinical Response Criteria and Early Response Criteria for Precision Oncology: Current State-ofthe-Art and Future Perspectives. Diagnostics (Basel). 2017;7(1):10.

16. Lencioni R, Llovet JM. Modified RECIST (mRECIST) assessment for hepatocellular carcinoma. Semin Liver Dis. 2010;30(1):52-60.

17. Macdonald DR, Cascino TL, Schold SC Jr, Cairncross JG. Response criteria for phase II studies of supratentorial malignant glioma. J Clin Oncol. 1990;8(7): 1277-80.

18. Wen PY, Macdonald DR, Reardon DA, Cloughesy TF, Sorensen AG, Galanis E, et al. Updated response assessment criteria for high-grade gliomas: response assessment in neuro-oncology working group. J Clin Oncol. 2010; 28(11):1963-72.

19. Hamaoka T, Madewell JE, Podoloff DA, Hortobagyi GN, Ueno NT. Bone imaging in metastatic breast cancer. J Clin Oncol. 2004;22(14):2942-53.

20. Cheson BD, Pfistner B, Juweid ME, Gascoyne RD, Specht L, Horning SJ, et al. Revised response criteria for malignant lymphoma. J Clin Oncol. 2007;25(5): 579-86.

21. Cheson BD, Fisher RI, Barrington SF, Cavalli F, Schwartz LH, Zucca E, et al. Recommendations for initial evaluation, staging, and response assessment of Hodgkin and non-Hodgkin lymphoma: the Lugano classification. J Clin Oncol. 2014:32(27):3059-68.

22. Choi H, Charnsangavej C, Faria SC, Macapinlac HA, Burgess MA, Patel SR, et al. Correlation of computed tomography and positron emission tomography in patients with metastatic gastrointestinal stromal tumor treated at a single institution with imatinib mesylate: proposal of new computed tomography response criteria. J Clin Oncol. 2007;25(13):1753-9.

23. Young H, Baum R, Cremerius U, Herholz K, Hoekstra O, Lammertsma AA et al. Measurement of clinical and subclinical tumour response using [18F]fluorodeoxyglucose and positron emission tomography: review and 1999 EORTC recommendations. European Organization for Research and Treatment of Cancer (EORTC) PET Study Group. Eur J Cancer. 1999;35(13): 1773-82.

24. Wahl RL, Jacene H, Kasamon Y, Lodge MA. From RECIST to PERCIST: Evolving Considerations for PET response criteria in solid tumors. J Nuc Med. 2009;50(Suppl 1(Suppl 1):122s-50s

25. Goldfarb L, Duchemann B, Chouahnia K, Zelek L, Soussan M. Monitoring anti-PD-1-based immunotherapy in non-small cell lung cancer with FDG PET: introduction of iPERCIST. EJNMMI Res. 2019;9(1):8.

26. Wolchok JD, Hoos A, O'Day S, Weber JS, Hamid O, Lebbé C, et al. Guidelines for the evaluation of immune therapy activity in solid tumors: immunerelated response criteria. Clin Cancer Res. 2009;15(23):7412-20.

27. Nishino M, Giobbie-Hurder A, Gargano M, Suda M, Ramaiya NH, Hodi FS Developing a common language for tumor response to immunotherapy: immune-related response criteria using unidimensional measurements. Clin Cancer Res. 2013;19(14):3936-43.

28. Seymour L, Bogaerts J, Perrone A, Ford R, Schwartz LH, Mandrekar S, et al. iRECIST: guidelines for response criteria for use in trials testing immunotherapeutics. Lancet Oncol. 2017;18(3):e143-e52.

29. Harry VN, Semple SI, Parkin DE, Gilbert FJ. Use of new imaging techniques to predict tumour response to therapy. Lancet Oncol. 2010;11(1):92-102.

30. World Health O. WHO handbook for reporting results of cancer treatment Geneva: World Health Organization; 1979.

31. Thiesse P, Ollivier L, Di Stefano-Louineau D, Négrier S, Savary J, Pignard K, et al. Response rate accuracy in oncology trials: reasons for interobserver 
variability. Groupe Français d'Immunothérapie of the Fédération Nationale des Centres de Lutte Contre le Cancer. J Clin Oncol. 1997;15(12):3507-14.

32. Kudo M, Kubo S, Takayasu K, Sakamoto M, Tanaka M, Ikai I, et al. Response Evaluation Criteria in Cancer of the Liver (RECICL) proposed by the Liver Cancer Study Group of Japan (2009 Revised Version). Hepatol Res. 2010; 40(7):686-92.

33. Cheson BD, Horning SJ, Coiffier B, Shipp MA, Fisher RI, Connors JM, et al. Report of an international workshop to standardize response criteria for non-Hodgkin's lymphomas. NCI Sponsored International Working Group. J Clin Oncol. 1999;17(4):1244

34. Calandri M, Solitro F, Angelino V, Moretti F, Veltri A. The role of radiology in the evaluation of the immunotherapy efficacy. J Thorac Dis. 2018;10(Suppl 13):1438-s46.

35. Wang GX, Kurra V, Gainor JF, Sullivan RJ, Flaherty KT, Lee SI, et al. Immune Checkpoint Inhibitor Cancer Therapy: Spectrum of Imaging Findings Radiographics. 2017;37(7):2132-44.

36. Khalil DN, Smith EL, Brentjens RJ, Wolchok JD. The future of cancer treatment: immunomodulation, CARs and combination immunotherapy. Nat Rev Clin Oncol. 2016;13(6):394.

37. Chiou VL, Burotto M. Pseudoprogression and Immune-Related Response in Solid Tumors. J Clin Oncol. 2015;33(31):3541-3.

38. Lee HY, Lee KS, Ahn MJ, Hwang HS, Lee JW, Park K, et al. New CT response criteria in non-small cell lung cancer: proposal and application in EGFR tyrosine kinase inhibitor therapy. Lung Cancer. 2011;73(1):63-9.

39. Abrams HL, Spiro R, Goldstein N. Metastases in carcinoma; analysis of 1000 autopsied cases. Cancer. 1950;3(1):74-85.

40. Coleman RE. Clinical features of metastatic bone disease and risk of skeletal morbidity. Clin Cancer Res. 2006;12(20 Pt 2):6243s-9s.

41. Yoon SH, Kim KW, Goo JM, Kim DW, Hahn S. Observer variability in RECISTbased tumour burden measurements: a meta-analysis. Eur J Cancer. 2016;53: 5-15.

42. Oxnard GR, Zhao B, Sima CS, Ginsberg MS, James LP, Lefkowitz RA, et al. Variability of lung tumor measurements on repeat computed tomography scans taken within 15 minutes. J Clin Oncol. 2011;29(23):3114-9.

43. Goldmacher GV, Conklin J. The use of tumour volumetrics to assess response to therapy in anticancer clinical trials. Br J Clin Pharmacol. 2012; 73(6):846-54.

44. Gavrielides MA, Kinnard LM, Myers KJ, Petrick N. Noncalcified lung nodules: volumetric assessment with thoracic CT. Radiology. 2009;251(1):26-37.

45. Zhao B, Schwartz LH, Moskowitz CS, Ginsberg MS, Rizvi NA, Kris MG. Lung cancer: computerized quantification of tumor response-initial results. Radiology. 2006;241(3):892-8.

46. Faghihi R, Zeinali-Rafsanjani B, Mosleh-Shirazi MA, Saeedi-Moghadam M, Lotfi M, Jalli R, et al. Magnetic Resonance Spectroscopy and its Clinical Applications: A Review. J Med Imaging Radiat Sci. 2017;48(3):233-53.

47. Faivre S, Zappa M, Vilgrain V, Boucher E, Douillard JY, Lim HY, et al. Changes in tumor density in patients with advanced hepatocellular carcinoma treated with sunitinib. Clin Cancer Res. 2011;17(13):4504-12.

48. Smith AD, Shah SN, Rini BI, Lieber ML, Remer EM, Morphology. Attenuation, Size, and Structure (MASS) criteria: assessing response and predicting clinical outcome in metastatic renal cell carcinoma on antiangiogenic targeted therapy. AJR Am J Roentgenol. 2010;194(6):1470-8.

49. Choi H, Charnsangavej C, de Castro Faria S, Tamm EP, Benjamin RS, Johnson $\mathrm{MM}$, et al. CT evaluation of the response of gastrointestinal stromal tumors after imatinib mesylate treatment: a quantitative analysis correlated with FDG PET findings. AJR Am J Roentgenol. 2004;183(6):1619-28.

50. Forner A, Ayuso C, Varela M, Rimola J, Hessheimer AJ, de Lope CR, et al. Evaluation of tumor response after locoregional therapies in hepatocellular carcinoma: are response evaluation criteria in solid tumors reliable? Cancer. 2009;115(3):616-23.

51. Llovet JM, Ricci S, Mazzaferro V, Hilgard P, Gane E, Blanc JF, et al. Sorafenib in advanced hepatocellular carcinoma. N Engl J Med. 2008;359(4):378-90.

52. Chun YS, Vauthey JN, Boonsirikamchai P, Maru DM, Kopetz S, Palavecino M, et al. Association of computed tomography morphologic criteria with pathologic response and survival in patients treated with bevacizumab for colorectal liver metastases. JAMA. 2009;302(21):2338-44.

53. van der Veldt AA, Meijerink MR, van den Eertwegh AJ, Haanen JB, Boven E. Choi response criteria for early prediction of clinical outcome in patients with metastatic renal cell cancer treated with sunitinib. Br J Cancer. 2010;102(5):803-9.

54. Miles KA. Perfusion CT for the assessment of tumour vascularity: which protocol? Br J Radiol. 2003;76:1:S36-42. Spec No.
55. Miles KA, Hayball M, Dixon AK. Colour perfusion imaging: a new application of computed tomography. Lancet. 1991;337(8742):643-5.

56. Carmeliet $\mathrm{P}$, Jain RK. Angiogenesis in cancer and other diseases. Nature. 2000;407(6801):249-57.

57. Ebos JM, Kerbel RS. Antiangiogenic therapy: impact on invasion, disease progression, and metastasis. Nat Rev Clin Oncol. 2011;8(4):210-21.

58. Bellomi M, Petralia G, Sonzogni A, Zampino MG, Rocca A. CT perfusion for the monitoring of neoadjuvant chemotherapy and radiation therapy in rectal carcinoma: initial experience. Radiology. 2007;244(2):486-93.

59. Hermans R, Meijerink M, Van den Bogaert W, Rijnders A, Weltens C, Lambin P. Tumor perfusion rate determined noninvasively by dynamic computed tomography predicts outcome in head-and-neck cancer after radiotherapy. Int J Radiat Oncol Biol Phys. 2003;57(5):1351-6.

60. Gray LH, Conger AD, Ebert M, Hornsey S, Scott OC. The concentration of oxygen dissolved in tissues at the time of irradiation as a factor in radiotherapy. Br J Radiol. 1953;26(312):638-48.

61. Vaupel P, Kelleher DK, Höckel M. Oxygen status of malignant tumors: pathogenesis of hypoxia and significance for tumor therapy. Semin Oncol. 2001;28(2 Suppl 8):29-35.

62. Figueiras RG, Padhani AR, Goh VJ, Vilanova JC, González SB, Martín CV, et al. Novel oncologic drugs: what they do and how they affect images. Radiographics. 2011;31(7):2059-91.

63. Fournier LS, Oudard S, Thiam R, Trinquart L, Banu E, Medioni J, et al. Metastatic renal carcinoma: evaluation of antiangiogenic therapy with dynamic contrast-enhanced CT. Radiology. 2010;256(2):511-8.

64. Han KS, Jung DC, Choi HJ, Jeong MS, Cho KS, Joung JY, et al. Pretreatment assessment of tumor enhancement on contrast-enhanced computed tomography as a potential predictor of treatment outcome in metastatic renal cell carcinoma patients receiving antiangiogenic therapy. Cancer. 2010;116(10):2332-42.

65. Jiang T, Kambadakone A, Kulkarni NM, Zhu AX, Sahani DV. Monitoring response to antiangiogenic treatment and predicting outcomes in advanced hepatocellular carcinoma using image biomarkers, CT perfusion, tumor density, and tumor size (RECIST). Invest Radiol. 2012;47(1):11-7.

66. Padhani AR, Khan AA. Diffusion-weighted (DW) and dynamic contrastenhanced (DCE) magnetic resonance imaging (MRI) for monitoring anticancer therapy. Target Oncol. 2010;5(1):39-52.

67. Kety SS. Theory of blood-tissue exchange and its application to measurement of blood flow. Methods Med Res. 1960;V:223-7.

68. Tofts PS, Brix G, Buckley DL, Evelhoch JL, Henderson E, Knopp MV, et al. Estimating kinetic parameters from dynamic contrast-enhanced T(1)weighted MRI of a diffusable tracer: standardized quantities and symbols. J Magn Reson Imaging. 1999;10(3):223-32.

69. Morabito R, Alafaci C, Pergolizzi S, Pontoriero A, lati G, Bonanno L, et al. DCE and DSC perfusion MRI diagnostic accuracy in the follow-up of primary and metastatic intra-axial brain tumors treated by radiosurgery with cyberknife. Radiat Oncol. 2019;14(1):65-.

70. El Khouli RH, Macura K, Jacobs MA, Khalil TH, Kamel IR, Dwyer A, et al. Dynamic contrast-enhanced MRI of the breast: quantitative method for kinetic curve type assessment. AJR Am J Roentgenol. 2009;193(4):W295-300.

71. Wedam SB, Low JA, Yang SX, Chow CK, Choyke P, Danforth D, et al. Antiangiogenic and antitumor effects of bevacizumab in patients with inflammatory and locally advanced breast cancer. J Clin Oncol. 2006;24(5):769-77.

72. de Lussanet QG, Backes WH, Griffioen AW, Padhani AR, Baeten Cl, van Baardwijk $A$, et al. Dynamic contrast-enhanced magnetic resonance imaging of radiation therapy-induced microcirculation changes in rectal cancer. Int J Radiat Oncol Biol Phys. 2005;63(5):1309-15.

73. Flaherty KT, Rosen MA, Heitjan DF, Gallagher ML, Schwartz B, Schnall MD, et al. Pilot study of DCE-MRI to predict progression-free survival with sorafenib therapy in renal cell carcinoma. Cancer Biol Ther. 2008;7(4):496501.

74. Alonzi R, Padhani AR, Taylor NJ, Stirling JJ, Saunders MI, Hoskin PJ. Physiological Changes within the Prostate Caused by Androgen Withdrawal. Clin Oncol. 2007;19(3):6.

75. Choi D, Lim HK, Kim SH, Lee WJ, Jang HJ, Lee JY, et al. Hepatocellular carcinoma treated with percutaneous radio-frequency ablation: usefulness of power Doppler US with a microbubble contrast agent in evaluating therapeutic response-preliminary results. Radiology. 2000;217(2):558-63.

76. Padhani AR, Leach MO. Antivascular cancer treatments: functional assessments by dynamic contrast-enhanced magnetic resonance imaging Abdom Imaging. 2005;30(3):324-41. 
77. Padhani AR, Liu G, Koh DM, Chenevert TL, Thoeny HC, Takahara T, et al. Diffusion-weighted magnetic resonance imaging as a cancer biomarker: consensus and recommendations. Neoplasia. 2009;11(2):102-25.

78. Koh DM, Collins DJ. Diffusion-weighted MRI in the body: applications and challenges in oncology. ARR American journal of roentgenology. 2007;188(6):1622-35.

79. Patterson DM, Padhani AR, Collins DJ. Technology insight: water diffusion MRI-a potential new biomarker of response to cancer therapy. Nat Clin Pract Oncol. 2008;5(4):220-33.

80. Gass A, Niendorf T, Hirsch JG. Acute and chronic changes of the apparent diffusion coefficient in neurological disorders-biophysical mechanisms and possible underlying histopathology. J Neurol Sci. 2001;186(Suppl 1):15-23.

81. Padhani AR, Koh DM. Diffusion MR imaging for monitoring of treatment response. Magn Reson Imaging Clin N Am. 2011;19(1):181-209.

82. Li SP, Padhani AR. Tumor response assessments with diffusion and perfusion MRI. J Magn Reson Imaging. 2012;35(4):745-63.

83. Kono K, Inoue $Y$, Nakayama K, Shakudo M, Morino M, Ohata K, et al. The role of diffusion-weighted imaging in patients with brain tumors. AJNR Am J Neuroradiol. 2001;22(6):1081-8.

84. Gluskin JS, Chegai F, Monti S, Squillaci E, Mannelli L. Hepatocellular Carcinoma and Diffusion-Weighted MRI: Detection and Evaluation of Treatment Response. J Cancer. 2016;7(11):1565-70.

85. Kubo T, Furuta T, Johan MP, Ochi M, Adachi N. Value of diffusion-weighted imaging for evaluating chemotherapy response in osteosarcoma: A metaanalysis. Mol Clin Oncol. 2017;7(1):88-92.

86. Hamstra DA, Chenevert TL, Moffat BA, Johnson TD, Meyer CR, Mukherji SK, et al. Evaluation of the functional diffusion map as an early biomarker of time-to-progression and overall survival in high-grade glioma. Proc Natl Acad Sci U S A. 2005:102(46):16759-64.

87. Usuda K, Iwai S, Funasaki A, Sekimura A, Motono N, Matoba M, et al. Diffusion-weighted magnetic resonance imaging is useful for the response evaluation of chemotherapy and/or radiotherapy to recurrent lesions of lung cancer. Translational oncology. 2019;12(5):699-704.

88. Zulfiqar M, Yousem DM, Lai H. ADC Values and Prognosis of Malignant Astrocytomas: Does Lower ADC Predict a Worse Prognosis Independent of Grade of Tumor?-A Meta-Analysis. Am J Roentgenol. 2013;200(3):624-9.

89. Koh DM, Blackledge M, Collins DJ, Padhani AR, Wallace T, Wilton B, et al. Reproducibility and changes in the apparent diffusion coefficients of solid tumours treated with combretastatin A4 phosphate and bevacizumab in a two-centre phase I clinical trial. Eur Radiol. 2009;19(11):2728-38.

90. Koh DM, Padhani AR. Diffusion-weighted MRI: a new functional clinical technique for tumour imaging. Br J Radiol. 2006;79(944):633-5.

91. Dzik-Jurasz A, Domenig C, George M, Wolber J, Padhani A, Brown G, et al. Diffusion MRI for prediction of response of rectal cancer to chemoradiation. Lancet. 2002;360(9329):307-8.

92. Cui Y, Zhang XP, Sun YS, Tang L, Shen L. Apparent diffusion coefficient: potential imaging biomarker for prediction and early detection of response to chemotherapy in hepatic metastases. Radiology. 2008;248(3):894-900.

93. Swinson DE, Jones JL, Richardson D, Cox G, Edwards JG, O'Byrne KJ. Tumour necrosis is an independent prognostic marker in non-small cell lung cancer: correlation with biological variables. Lung Cancer. 2002;37(3):235-40.

94. Sun YS, Zhang XP, Tang L, Ji JF, Gu J, Cai Y, et al. Locally advanced rectal carcinoma treated with preoperative chemotherapy and radiation therapy: preliminary analysis of diffusion-weighted MR imaging for early detection of tumor histopathologic downstaging. Radiology. 2010;254(1):170-8.

95. Koh DM, Scurr E, Collins D, Kanber B, Norman A, Leach MO, et al. Predicting response of colorectal hepatic metastasis: value of pretreatment apparent diffusion coefficients. AJR Am J Roentgenol. 2007;188(4):1001-8.

96. Park SH, Moon WK, Cho N, Song IC, Chang JM, Park IA, et al. Diffusionweighted MR imaging: pretreatment prediction of response to neoadjuvant chemotherapy in patients with breast cancer. Radiology. 2010;257(1):56-63.

97. Lo CH, Huang WY, Hsiang CW, Lee MS, Lin CS, Yang JF, et al. Prognostic Significance of Apparent Diffusion Coefficient in Hepatocellular Carcinoma Patients treated with Stereotactic Ablative Radiotherapy. Sci Rep. 2019;9(1):14157.

98. Wen Q, Jalilian L, Lupo JM, Molinaro AM, Chang SM, Clarke J, et al. Comparison of ADC metrics and their association with outcome for patients with newly diagnosed glioblastoma being treated with radiation therapy, temozolomide, erlotinib and bevacizumab. J Neuro-oncology. 2015;121(2):331-9.

99. Yankeelov TE, Lepage M, Chakravarthy A, Broome EE, Niermann KJ, Kelley $M C$, et al. Integration of quantitative DCE-MRI and ADC mapping to monitor treatment response in human breast cancer: initial results. Magn Reson Imaging. 2007;25(1):1-13
100. Hayashida Y, Yakushiji T, Awai K, Katahira K, Nakayama Y, Shimomura O, et al. Monitoring therapeutic responses of primary bone tumors by diffusion-weighted image: initial results. Eur Radiol. 2006;16(12):2637-43.

101. Brown TR, Kincaid BM, Ugurbil K. NMR chemical shift imaging in three dimensions. Proc Natl Acad Sci U S A. 1982;79(11):3523-6.

102. van der Graaf M. In vivo magnetic resonance spectroscopy: basic methodology and clinical applications. Eur Biophys J. 2010;39(4):527-40.

103. Skoch A, Jiru F, Bunke J. Spectroscopic imaging: Basic principles. Eur J Radiol. 2008;67(2):230-9.

104. Drost DJ, Riddle WR, Clarke GD. Proton magnetic resonance spectroscopy in the brain: report of AAPM MR Task Group \#9. Med Phys. 2002;29(9):2177-97.

105. Herminghaus S, Dierks T, Pilatus U, Möller-Hartmann W, Wittsack J, Marquardt G, et al. Determination of histopathological tumor grade in neuroepithelial brain tumors by using spectral pattern analysis of in vivo spectroscopic data. J Neurosurg. 2003;98(1):74-81.

106. Brandão LA, Castillo M. Adult Brain Tumors: Clinical Applications of Magnetic Resonance Spectroscopy. Magn Reson Imaging Clin N Am. 2016; 24(4):781-809.

107. Howe FA, Barton SJ, Cudlip SA, Stubbs M, Saunders DE, Murphy M, et al. Metabolic profiles of human brain tumors using quantitative in vivo $1 \mathrm{H}$ magnetic resonance spectroscopy. Magn Reson Med. 2003;49(2):223-32.

108. Roebuck JR, Cecil KM, Schnall MD, Lenkinski RE. Human breast lesions: characterization with proton MR spectroscopy. Radiology. 1998;209(1):269-75.

109. Aribal E, Asadov R, Ramazan A, Ugurlu M, Kaya H. Multiparametric breast MRI with 3T: Effectivity of combination of contrast enhanced MRI, DWI and $1 \mathrm{H}$ single voxel spectroscopy in differentiation of Breast tumors. Eur J Radiol. 2016;85(5):979-86.

110. Wang X, Wang XJ, Song HS, Chen LH. 1H-MRS evaluation of breast lesions by using total choline signal-to-noise ratio as an indicator of malignancy: a meta-analysis. Med Oncol. 2015;32(5):160.

111. Jagannathan NR, Kumar M, Seenu V, Coshic O, Dwivedi SN, Julka PK, et al. Evaluation of total choline from in-vivo volume localized proton MR spectroscopy and its response to neoadjuvant chemotherapy in locally advanced breast cancer. Br J Cancer. 2001;84(8):1016-22.

112. Meisamy S, Bolan PJ, Baker EH, Bliss RL, Gulbahce E, Everson LI, et al. Neoadjuvant chemotherapy of locally advanced breast cancer: predicting response with in vivo (1)H MR spectroscopy-a pilot study at 4 T. Radiology. 2004;233(2):424-31.

113. Panebianco V, Sciarra A, Lisi D, Galati F, Buonocore V, Catalano C, et al. Prostate cancer: 1 HMRS-DCEMR at 3T versus [(18)F]choline PET/CT in the detection of local prostate cancer recurrence in men with biochemical progression after radical retropubic prostatectomy (RRP). Eur J Radiol. 2012;81(4):700-8.

114. Fütterer JJ, Heijmink SWTPJ, Scheenen TWJ, Veltman J, Huisman HJ, Vos P, et al Prostate Cancer Localization with Dynamic Contrast-enhanced MR Imaging and Proton MR Spectroscopic Imaging. Radiology. 2006;241(2):449-58.

115. García-Figueiras R, Baleato-González S, Padhani AR, Oleaga L, Vilanova JC, Luna $A$, et al. Proton magnetic resonance spectroscopy in oncology: the fingerprints of cancer? Diagn Interv Radiol. 2016;22(1):75-89.

116. Payne GS, Schmidt M, Morgan VA, Giles S, Bridges J, Ind T, et al. Evaluation of magnetic resonance diffusion and spectroscopy measurements as predictive biomarkers in stage 1 cervical cancer. Gynecol Oncol. 2010;116(2):246-52.

117. Takeuchi M, Matsuzaki K, Harada M. Differentiation of benign and malignant uterine corpus tumors by using proton MR spectroscopy at 3T: preliminary study. Eur Radiol. 2011;21(4):850-6.

118. Kim MJ, Lee SJ, Lee JH, Kim SH, Chun HK, Kim SH, et al. Detection of rectal cancer and response to concurrent chemoradiotherapy by proton magnetic resonance spectroscopy. Magn Reson Imaging. 2012;30(6):848-53.

119. Van den Abbeele AD. The lessons of GIST-PET and PET/CT: a new paradigm for imaging. Oncologist. 2008;13(Suppl 2):8-13.

120. Dose Schwarz J, Bader M, Jenicke L, Hemminger G, Jänicke F, Avril N. Early prediction of response to chemotherapy in metastatic breast cancer using sequential 18F-FDG PET. J Nucl Med. 2005;46(7):1144-50.

121. Wieder HA, Brücher BL, Zimmermann F, Becker K, Lordick F, Beer A, et al. Time course of tumor metabolic activity during chemoradiotherapy of esophageal squamous cell carcinoma and response to treatment. J Clin Oncol. 2004;22(5):900-8

122. Fischer BM, Mortensen J, Højgaard L. Positron emission tomography in the diagnosis and staging of lung cancer: a systematic, quantitative review. Lancet Oncol. 2001;2(11):659-66.

123. Berghmans T, Dusart M, Paesmans M, Hossein-Foucher C, Buvat I, Castaigne C, et al. Primary tumor standardized uptake value (SUVmax) measured on 
fluorodeoxyglucose positron emission tomography (FDG-PET) is of prognostic value for survival in non-small cell lung cancer (NSCLC): a systematic review and meta-analysis (MA) by the European Lung Cancer Working Party for the IASLC Lung Cancer Staging Project. J Thorac Oncol. 2008;3(1):6-12.

124. Costelloe CM, Macapinlac HA, Madewell JE, Fitzgerald NE, Mawlawi OR, Rohren EM, et al. 18F-FDG PET/CT as an indicator of progression-free and overall survival in osteosarcoma. J Nucl Med. 2009;50(3):340-7.

125. Weber WA, Wieder H. Monitoring chemotherapy and radiotherapy of solid tumors. Eur J Nucl Med Mol Imaging. 2006;33(Suppl 1):27-37.

126. Stroobants S, Goeminne J, Seegers M, Dimitrijevic S, Dupont P, Nuyts J, et al. 18FDG-Positron emission tomography for the early prediction of response in advanced soft tissue sarcoma treated with imatinib mesylate (Glivec). Eur J Cancer. 2003;39(14):2012-20.

127. Wahl RL, Zasadny K, Helvie M, Hutchins GD, Weber B, Cody R. Metabolic monitoring of breast cancer chemohormonotherapy using positron emission tomography: initial evaluation. J Clin Oncol. 1993;11(11):2101-11.

128. Fischer B, Lassen U, Mortensen J, Larsen S, Loft A, Bertelsen A, et al. Preoperative staging of lung cancer with combined PET-CT. N Engl J Med. 2009;361(1):32-9.

129. Scott AM, Gunawardana DH, Kelley B, Stuckey JG, Byrne AJ, Ramshaw JE, et al. PET changes management and improves prognostic stratification in patients with recurrent colorectal cancer: results of a multicenter prospective study. J Nucl Med. 2008;49(9):1451-7.

130. McDermott GM, Welch A, Staff RT, Gilbert FJ, Schweiger L, Semple SI, et al. Monitoring primary breast cancer throughout chemotherapy using FDGPET. Breast Cancer Res Treat. 2007;102(1):75-84.

131. Semple SI, Gilbert FJ, Redpath TW, Staff RT, Ahearn TS, Welch AE, et al. The relationship between vascular and metabolic characteristics of primary breast tumours. Eur Radiol. 2004;14(11):2038-45.

132. Koçak B, Durmaz E, Ateş E, Kllıçkesmez Ö. Radiomics with artificial intelligence: a practical guide for beginners. Diagn Interv Radiol. 2019;25(6): 485-95

133. Gatenby RA, Grove O, Gillies RJ. Quantitative imaging in cancer evolution and ecology. Radiology. 2013;269(1):8-15.

134. Kumar V, Gu Y, Basu S, Berglund A, Eschrich SA, Schabath MB, et al. Radiomics: the process and the challenges. Magn Reson Imaging. 2012; 30(9):1234-48.

135. Lambin P, Rios-Velazquez E, Leijenaar R, Carvalho S, van Stiphout RG, Granton P, et al. Radiomics: extracting more information from medical images using advanced feature analysis. Eur J Cancer. 2012;48(4):441-6.

136. Zhou M, Scott J, Chaudhury B, Hall L, Goldgof D, Yeom KW, et al. Radiomics in Brain Tumor: Image Assessment, Quantitative Feature Descriptors, and Machine-Learning Approaches. AJNR American journal of neuroradiology. 2018;39(2):208-16.

137. Coroller TP, Bi WL, Huynh E, Abedalthagafi M, Aizer AA, Greenwald NF, et al, Radiographic prediction of meningioma grade by semantic and radiomic features. PloS one. 2017;12(11):e0187908.

138. Wu J, Aguilera T, Shultz D, Gudur M, Rubin DL, Loo BW Jr, et al. Early-Stage Non-Small Cell Lung Cancer: Quantitative Imaging Characteristics of (18)F Fluorodeoxyglucose PET/CT Allow Prediction of Distant Metastasis. Radiology. 2016;281(1):270-8

139. Goh V, Ganeshan B, Nathan P, Juttla JK, Vinayan A, Miles KA. Assessment of response to tyrosine kinase inhibitors in metastatic renal cell cancer: $C T$ texture as a predictive biomarker. Radiology. 2011;261(1):165-71.

140. Parmar C, Grossmann P, Rietveld D, Rietbergen MM, Lambin P, Aerts HJ. Radiomic Machine-Learning Classifiers for Prognostic Biomarkers of Head and Neck Cancer. Front Oncol. 2015;5:272.

141. Gastounioti A, Conant EF, Kontos D. Beyond breast density: a review on the advancing role of parenchymal texture analysis in breast cancer risk assessment. Breast Cancer Res. 2016;18(1):91.

142. Ginsburg SB, Algohary A, Pahwa S, Gulani V, Ponsky L, Aronen HJ, et al. Radiomic features for prostate cancer detection on MRI differ between the transition and peripheral zones: Preliminary findings from a multiinstitutional study. J Magn Reson Imaging. 2017;46(1):184-93.

143. Cozzi L, Dinapoli N, Fogliata A, Hsu WC, Reggiori G, Lobefalo F, et al. Radiomics based analysis to predict local control and survival in hepatocellular carcinoma patients treated with volumetric modulated arc therapy. BMC Cancer. 2017;17(1):829.
144. Bera K, Velcheti V, Madabhushi A. Novel Quantitative Imaging for Predicting Response to Therapy: Techniques and Clinical Applications. Am Soc Clin Oncol Educ Book. 2018;38(38):1008-18.

145. Huynh E, Coroller TP, Narayan V, Agrawal V, Romano J, Franco I, et al. Associations of Radiomic Data Extracted from Static and Respiratory-Gated CT Scans with Disease Recurrence in Lung Cancer Patients Treated with SBRT. PloS one. 2017;12(1):e0169172.

146. Rakshit S, Orooji M, Beig N, Alilou M, Pennell NA, Stevenson J, et al. Evaluation of radiomic features on baseline $C T$ scan to predict clinical benefit for pemetrexed based chemotherapy in metastatic lung adenocarcinoma. J Clin Oncol. 2016;34(15 suppl):11582-

147. Velcheti V, Alilou M, Khunger M, Thawani R, Madabhushi A. Changes in computer extracted features of vessel tortuosity on $\mathrm{CT}$ scans post-treatment in responders compared to non-responders for non-small cell lung cancer on immunotherapy. J Clin Oncol. 2017:35(15_suppl):11518-

148. Xie Y, Khunger M, Thawani R, Velcheti V, Madabhushi A. Evolution of radiomic features on serial $C T$ scans as an imaging based biomarker for evaluating response in patients with non-small cell lung cancer treated with nivolumab. J Clin Oncol. 2017;35(15_suppl):e14534-e.

149. Tang C, Hobbs B, Amer A, Li X, Behrens C, Canales JR, et al. Development of an Immune-Pathology Informed Radiomics Model for Non-Small Cell Lung Cancer. Scientific reports. 2018:8(1):1922.

150. Murphya P, Koh DM. Imaging in clinical trials. Cancer Imaging. 2010;10(1A): 74-82.

151. Miles K. Radiomics for personalised medicine: the long road ahead. Br J Cancer. 2020:122(7):929-30

\section{Publisher's Note}

Springer Nature remains neutral with regard to jurisdictional claims in published maps and institutional affiliations.

Ready to submit your research? Choose BMC and benefit from:

- fast, convenient online submission

- thorough peer review by experienced researchers in your field

- rapid publication on acceptance

- support for research data, including large and complex data types

- gold Open Access which fosters wider collaboration and increased citations

- maximum visibility for your research: over $100 \mathrm{M}$ website views per year

At $\mathrm{BMC}$, research is always in progress.

Learn more biomedcentral.com/submissions 